\title{
Photoinduced Changes in Aromaticity Facilitate Electrocyclization of Dithienylbenzene Switches
}

\author{
Baswanth Oruganti,* Péter Pál Kalapos, Varada Bhargav, Gábor London,* and Bo Durbeej* \\ Cite This: J. Am. Chem. Soc. 2020, 142, 13941-13953 \\ Read Online
}

ABSTRACT: The concepts of excited-state aromaticity and antiaromaticity have in recent years with increasing frequency been invoked to rationalize the photochemistry of cyclic conjugated organic compounds, with the long-term goal of using these concepts to improve the reactivities of such compounds toward different photochemical transformations. In this regard, it is of particular interest to assess how the presence of a benzene motif affects photochemical reactivity, as benzene is well-known to completely change its aromatic character in its lowest excited states. Here, we investigate how a benzene motif influences the photoinduced electrocyclization of dithienylethenes, a major class of molecular switches. Specifically, we report on the synthesis of a dithienylbenzene switch where the typical

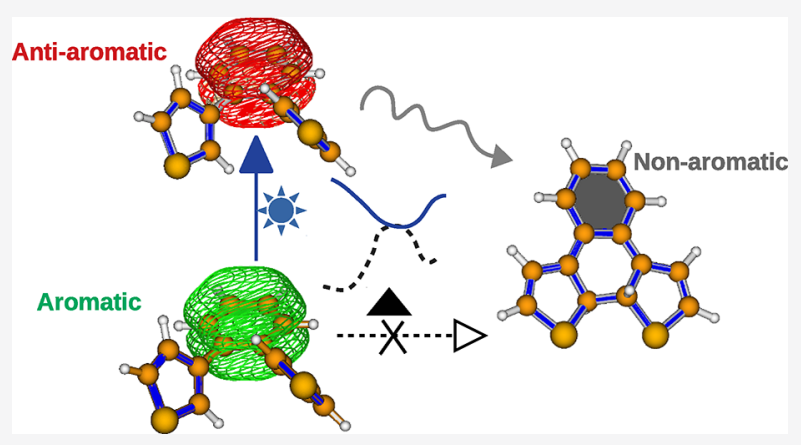
nonaromatic, ethene-like motif bridging the two thienyl units is replaced by a benzene motif, and show that this compound undergoes electrocyclization upon irradiation with UV-light. Furthermore, through a detailed quantum chemical analysis, we demonstrate that the electrocyclization is driven jointly and synergistically by the loss of aromaticity in this motif from the formation of a reactive, antiaromatic excited state during the initial photoexcitation, and by the subsequent relief of this antiaromaticity as the reaction progresses from the Franck-Condon region. Overall, we conclude that photoinduced changes in aromaticity facilitate the electrocyclization of dithienylbenzene switches.

\section{INTRODUCTION}

The concept of aromaticity is widely used in organic chemistry to predict and rationalize structures and reactivities of cyclic conjugated molecules residing in their electronic ground state. It was first applied to electronic excited states by Dewar ${ }^{1}$ and Zimmerman $^{2}$ in the 1960s to explain the formation of fourmembered rings in photochemical electrocyclization reactions. These authors proposed that such reactions proceed through aromatic transition structures, which are also known to mediate thermal electrocyclization, ${ }^{1-3}$ sigmatropic rearrangement, ${ }^{3,4}$ nonpericyclic ring-closure, ${ }^{3,5}$ and carbonyl-olefin metathesis $^{6}$ reactions. Subsequently, Baird ${ }^{7}$ used semiempirical molecular orbital theory calculations to formulate rules for aromaticity and antiaromaticity in the lowest triplet excited state $\left(T_{1}\right)$ of cyclic conjugated hydrocarbons. These rules, which are the reverse of Huckel's rules for the ground state, assert that $4 n+2$ and $4 n \pi$-electron systems are respectively antiaromatic and aromatic in $\mathrm{T}_{1}$. As argued by Aihara in 1978, it follows from Baird's rules that reactions of benzene that are energetically hindered in the ground state due to a loss of aromaticity, are favored in $\mathrm{T}_{1}$ due to a loss of antiaromaticity. However, unlike consequences of Huckel's rules, this implication of Baird's rules was not put to immediate test.

Much later, in 2008, 9,10 Karadakov demonstrated using multiconfigurational quantum chemical calculations that Baird's rules apply also to the lowest singlet excited state
$\left(S_{1}\right)$ of cyclobutadiene, ${ }^{9}$ benzene, ${ }^{9}$ and cyclooctatetraene. ${ }^{10}$ This triggered a renewed interest in excited-state aromaticity (ESA), both in terms of obtaining spectroscopic evidence for the concept ${ }^{11-14}$ and applying it to the design of novel synthetic protocols. ${ }^{15-17}$ Furthermore, this trend led to the discovery of ways of tuning ESA through steric and electronic substituent effects ${ }^{18}$ and to the development of strategies for using ESA to modulate double-bond photoisomerization, ${ }^{19-22}$ proton-transfer, ${ }^{21,23-25}$ electrocyclization, ${ }^{26}$ conformationalplanarization, ${ }^{27-29}$ and photodissociation ${ }^{30}$ reactions.

In a recent review ${ }^{21}$ outlining how ESA may improve photochemical reactivity, two broad strategies were discussed, as illustrated in Scheme 1. The first involves utilizing a gain of antiaromaticity (or a loss of aromaticity) from the initial electronic excitation, ${ }^{23}$ and the second involves exploiting a gain of aromaticity during the subsequent geometric relaxation from the vertically excited Franck-Condon (FC) point. $^{20,22}$ Interestingly, however, a recent investigation ${ }^{26}$ noted that

Received: June 11, 2020

Published: July 15, 2020 
Scheme 1. (a) Facilitating an Excited-State Proton Transfer Reaction through a Gain of Anti-Aromaticity in the Excited State ${ }^{23}$ and (b) Facilitating a $Z / E$ Photoisomerization Reaction through a Gain of Aromaticity in the Excited State ${ }^{20,22}$

(a)

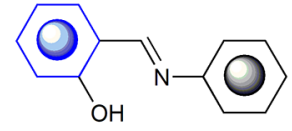

aromatic

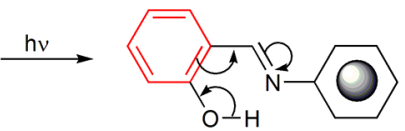

anti-aromatic
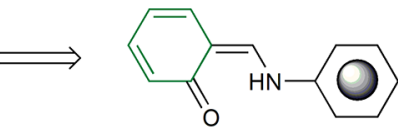

non-aromatic (b)

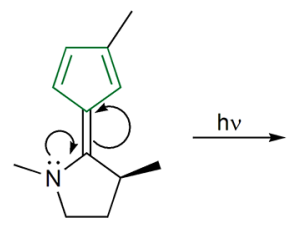

non-aromatic

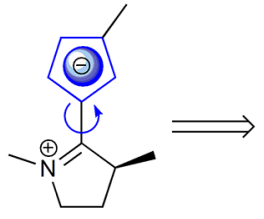

aromatic

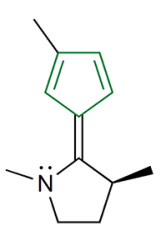

non-aromatic

Scheme 2. Chemical Structures of the Open (1a), Closed (1b), and Closed-Oxidized (1c) Forms of the Dithienylbenzene Switch Studied in This Work

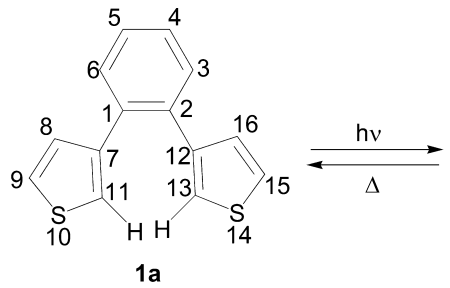

$1 \mathrm{a}$

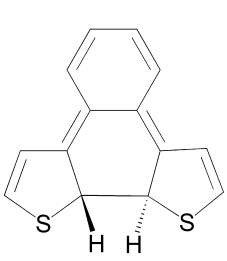

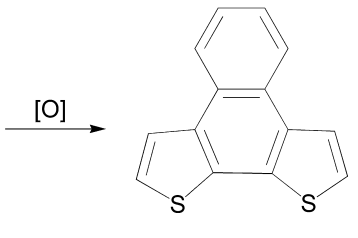

1c photoinduced changes in aromaticity need not always influence photochemical reactivity in a positive direction. Specifically, through transient absorption spectroscopy and time-dependent density functional theory (TD-DFT) studies of dihydroazulene-vinylheptafulvene photoswitches operated through electrocyclization reactions, it was found that the loss of aromaticity in a benzene motif from the initial electronic excitation hampers the photochemical reactivity by increasing an already existing barrier along the excited-state potential energy surface (PES). ${ }^{26}$ In this light, it is worthwhile to investigate whether a similar conclusion is applicable also to other types of photoswitches utilizing electrocyclization reactions and featuring a benzene motif.

To this end, we here consider dithienylethene switches, which are one of the most extensively studied class of electrocyclization-based photoswitches, ${ }^{31-39}$ with applications in photopharmacology, ${ }^{40,41}$ molecular electronics, ${ }^{34,38,42,43}$ and in the design of complex functional materials. ${ }^{44-46}$ Specifically, we report on the synthesis and the experimental and computational characterization of a dithienylbenzene switch where the typical nonaromatic, ethene-like motif ${ }^{31-39}$ bridging the two thienyl units, is replaced by an aromatic benzene motif. The corresponding switch in its isomeric open (1a) and closed (1b) forms, and in a closed-oxidized form (1c), are shown in Scheme 2.

Photoswitches like 1a with an aromatic benzene $\pi$-linker have a potential key advantage over those with a nonaromatic linker in that the energy stored in the ring-closed isomer $\mathbf{1 b}$ is generally larger, because of the transformation of the benzene motif in $\mathbf{1 a}$ into a nonaromatic cyclohexadiene motif in $\mathbf{1} \mathbf{b}$. This makes these switches interesting candidates as molecular solar thermal energy (MOST) storage systems. ${ }^{47-50}$ However, a recent study ${ }^{51}$ on dithienylethene switches with pyrazinebased aromatic $\pi$-linkers predicted the photocyclization of such switches to be hindered by the energetic expense associated with the ensuing loss of ground-state aromaticity. Although reached systematically through absorption spectroscopy and crystallographic measurements, and with support from DFT computations, $^{51}$ this prediction seems to us somewhat simplistic. In fact, it relies essentially on the assumption that the ground-state aromaticity of the $\pi$-linker remains unchanged in the excited state. However, following the foregoing discussion of ESA based on Baird's rules ${ }^{7}$ and their extensions, ${ }^{9,10,52}$ this assumption is not valid for a switch featuring a benzene $\pi$-linker. Furthermore, it is well-known that the ground-state aromaticity of the thienyl units does not impede the photocyclization of dithienylethene switches. ${ }^{34,37,38}$ Therefore, it seems natural to expect the same to hold true for the ground-state aromaticity of the $\pi$-linker. It should also be mentioned that Kitagawa and co-workers ${ }^{53}$ recently reported spectroscopic evidence for photocyclization of a fluorinated derivative of $\mathbf{1 a}$, in the form of a large absorption red-shift upon UV irradiation. As pointed out by these authors, ${ }^{53}$ the nondetection of the ring-closed isomer in previous studies of such photoswitches is not necessarily an indication that photocyclization does not occur but is rather a consequence of the fact that formation of the ring-closed isomer is immediately followed by fast thermal cycloreversion (that restores the ground-state aromaticity of the $\pi$-linker).

In this work, the potential problem with detecting the ringclosed isomer $\mathbf{1 b}$ is bypassed by allowing, as shown in Scheme 2 , for its subsequent oxidation to the more stable product $\mathbf{1 c}$, which is isolated and characterized by means of UV-vis absorption and NMR spectroscopy. This oxidation is facilitated by the presence of hydrogens instead of alkyl groups at the ring-closing $\mathrm{C} 11$ and $\mathrm{C} 13$ positions. In particular, this work presents detailed computational evidence supporting the idea that photoinduced changes in the aromaticity of the benzene motif of dithienylbenzene switch 1a exerts a distinctly positive influence on the photocyclization reactivity of this compound. 


\section{RESULTS AND DISCUSSION}

\subsection{Experimental UV-vis Absorption and ${ }^{1} \mathrm{H}$ NMR} Spectra. The UV-vis absorption spectra of 1a shown in Figure 1 display high-energy bands and do not exhibit any

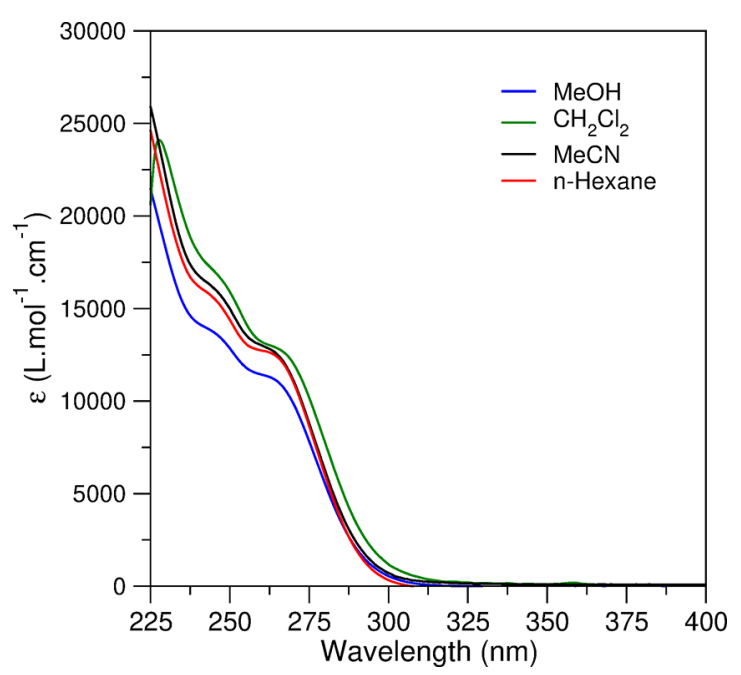

Figure 1. UV-vis absorption spectra of $\mathbf{1 a}$ in different solvents.

solvent dependence, which is further corroborated by spectra recorded in additional solvents given in Figure S1 of the Supporting Information (SI). Upon irradiation of $\mathbf{1 a}$ in $\mathrm{MeCN}$ with UV-light of $254 \mathrm{~nm}$, no apparent color change was observed. However, as illustrated in Figure 2, new absorption

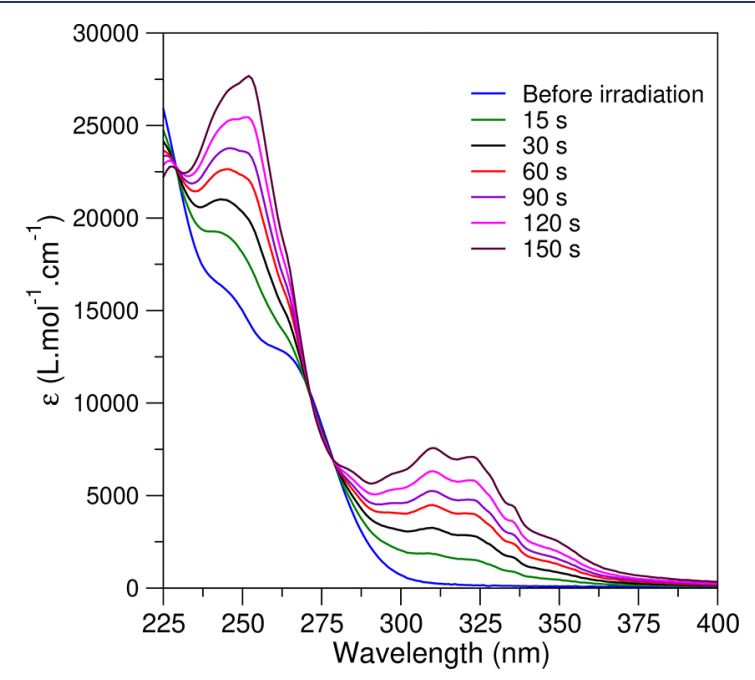

Figure 2. Irradiation of $\mathbf{1 a}$ in $\mathrm{MeCN}$ solution at $254 \mathrm{~nm}$.

bands appeared in the near-UV region. Prolonged irradiation of the sample produced clear isosbestic points at 229, 271, and $279 \mathrm{~nm}$, indicating the formation of a single, well-defined product. This photochemical transformation was found irreversible and, as can be inferred from Figures S2-S4 of the SI, quite insensitive to the nature of the solvent.

The gradual change of the initial UV-vis absorption spectrum of $1 \mathrm{a}$ in Figure 2 upon irradiation at $254 \mathrm{~nm}$ suggests that the high-energy UV-light induces a 6-electron electrocyclization of this compound. The resulting ring-closed product $\mathbf{1 b}$ is expected to undergo either of two reactions: thermal cycloreversion back to the parent species (1a), which is favored by the regeneration of the three aromatic rings, or oxidation by atmospheric $\mathrm{O}_{2}$ to yield a highly stable, aromatic $18 \pi$-electron compound (1c) and $\mathrm{H}_{2} \mathrm{O}$. In order to gain structural insight into which of these two reactions is more likely, the photochemical transformation was followed by ${ }^{1} \mathrm{H}$ NMR spectroscopy. The results are presented in Figure 3 and in Figures S6-S8 of the SI. As can be seen from Figures 3 and S6, upon irradiation of a solution of $1 \mathrm{a}$ in $\mathrm{CD}_{3} \mathrm{CN}$, a new set of peaks appears in the ${ }^{1} \mathrm{H}$ NMR spectrum, upfield to the signals before irradiation, while the intensities of the original signals are reduced. Gratifyingly, based on an analysis of the new peaks (see Figure S7), it was found that they correspond to 1c. Furthermore, consistent with this interpretation, water is the only observed byproduct (see Figure S8). Although 1c has previously been prepared by alternative methods, ${ }^{54}$ its photochemical generation has not been reported before.

Besides synthesizing 1a and generating 1c photochemically, we also synthesized a tetramethylated derivative of 1 a bearing methyl substituents instead of hydrogens both at the "outer" C9 and $\mathrm{C} 15$ positions and the ring-closing $\mathrm{C} 11$ and $\mathrm{C} 13$ positions. For this compound, which has not been prepared earlier and is denoted $\mathbf{M e}_{\mathbf{4}} \mathbf{- 1 a}$ in Scheme 3, no apparent change of its absorption spectrum (see Figure S5 of the SI) was observed upon irradiation with UV-light. This may indicate that the ring-closed species, being relatively insusceptible to oxidation by the presence of the C11 and C13 methyl groups, undergoes a fast thermal cycloreversion that precludes its spectroscopic detection. ${ }^{53}$ We will return to this issue in section 2.2.

2.2. Thermal Electrocyclization and Oxidation. The first task for the computational part of this work is to clarify how probable or improbable the thermal electrocyclization of 1a is. Such an assessment will provide a frame of reference for the subsequent modeling of the photoinduced electrocyclization process. Before this assessment, however, it should be noted that previous studies on diarylethene switches have observed two possible conformations for the open isomer: a parallel conformation with the aryl rings in mirror symmetry, and an anti-parallel conformation with the aryl rings in $C_{2}$ symmetry. ${ }^{33,34,37}$ Analogously, the open isomer 1a also exhibits parallel and anti-parallel conformations, shown in Figure 4 and hereafter denoted 1a-p and 1a-ap, respectively. As can be seen in Table 1, each of the four DFT methods employed for the calculations, which were performed using an $\mathrm{SMD}^{55}$ continuum solvation model representation of a $\mathrm{MeCN}$ solvent, yields free energies of 1a-p and 1a-ap that are very similar. Furthermore (see Table S1 of the SI), the predicted freeenergy barriers for the thermal interconversion between these conformations are small, only $11-25 \mathrm{~kJ} \mathrm{~mol}^{-1}$, which suggest very fast interconversion processes. Overall, these findings are consistent with previously reported NMR data on dithienylethene switches indicating that the two conformations are equally populated under ambient conditions. ${ }^{33,34,38}$ Moreover, these studies showed that the parallel conformation does not undergo photocyclization. ${ }^{33,34}$ For this reason, only the 1a-ap conformation was considered in the present modeling of the thermal electrocyclization and photocyclization reactions of $\mathbf{1 a}$.

While the free-energy barriers for the 1a-p $\leftrightarrow$ 1a-ap interconversion are small, Table 2 shows that each of the four DFT methods predicts a barrier for the $\mathbf{1 a}$-ap $\rightarrow \mathbf{1 b}$ thermal electrocyclization of such magnitude (183-197 kJ $\mathrm{mol}^{-1}$ ) that the reaction cannot be induced thermally under reasonable conditions. This is in accordance with the reaction 
(a)<smiles>Cc1ccc(-c2cccs2)c(-c2c(C)sc3ccccc23)c1C</smiles>
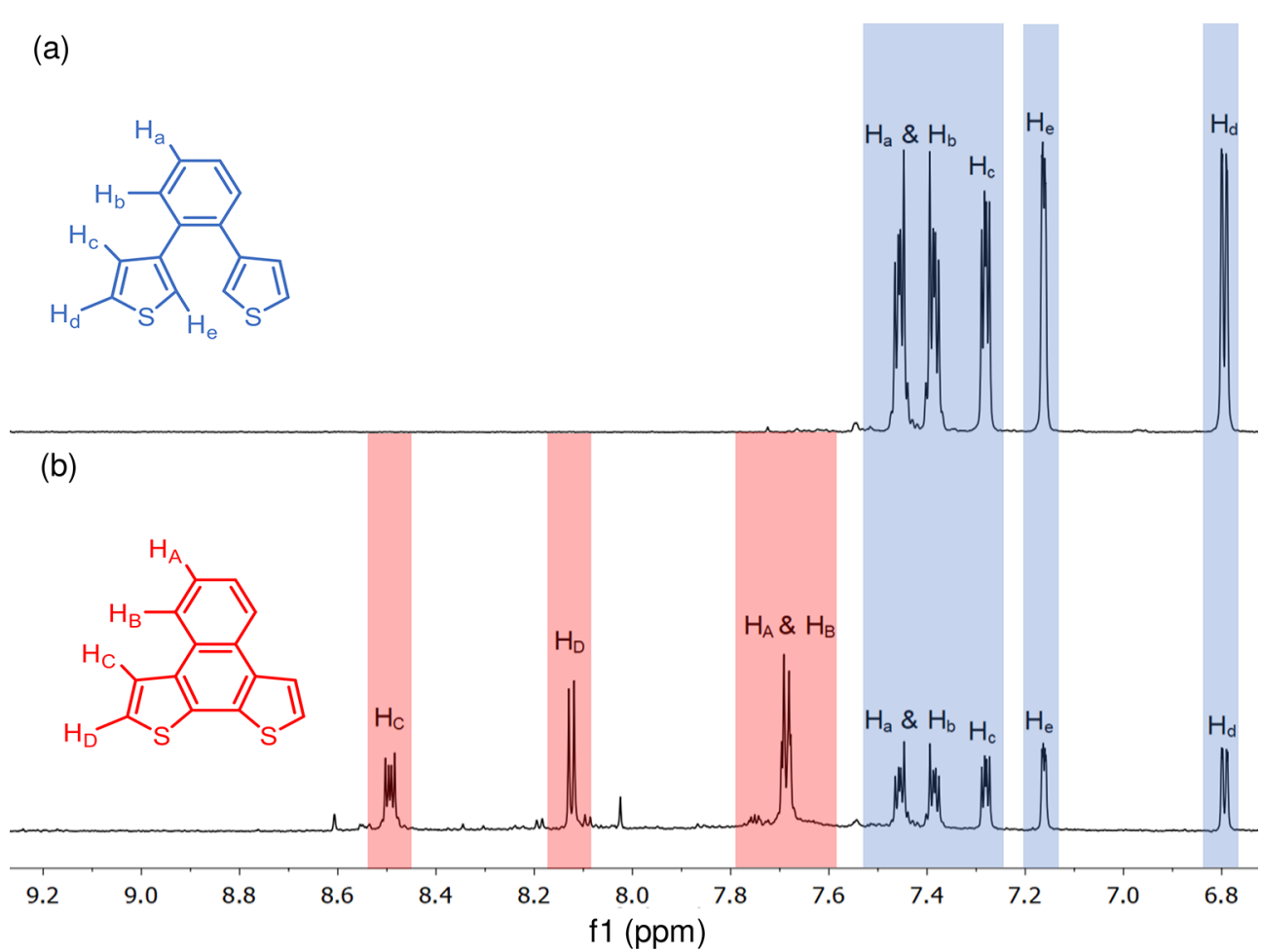

Figure 3. Irradiation of 1a in $\mathrm{CD}_{3} \mathrm{CN}$ at $254 \mathrm{~nm}$, followed by ${ }^{1} \mathrm{H}$ NMR spectroscopy. (a) ${ }^{1} \mathrm{H}$ NMR spectrum before irradiation. (b) ${ }^{1} \mathrm{H}$ NMR spectrum after $90 \mathrm{~min}$.

Scheme 3. Chemical Structures of Additional Dithienylbenzene Switches Studied in This Work

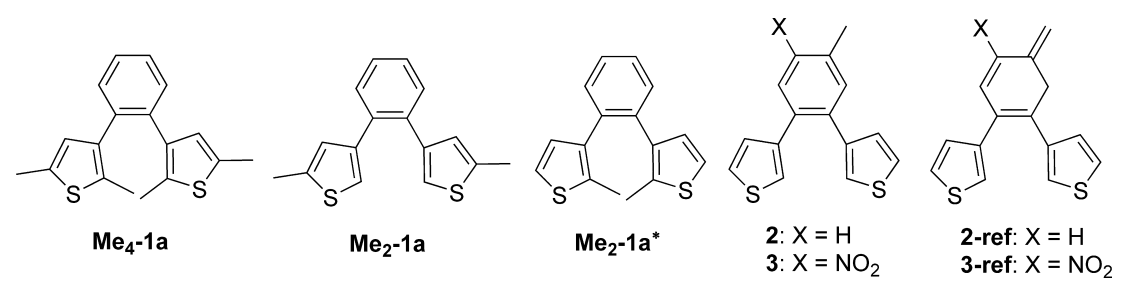

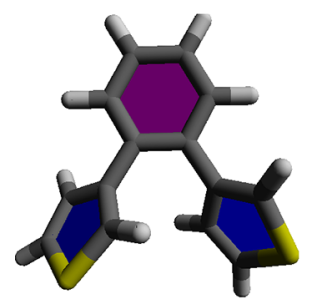

$1 a-p$

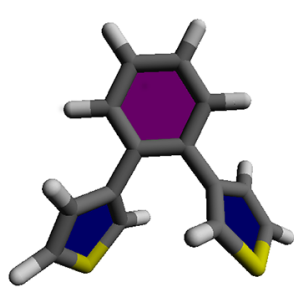

1a-ap

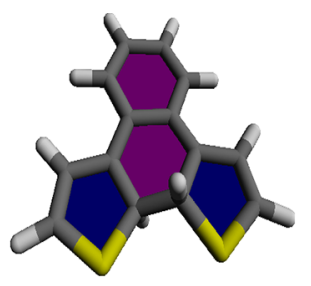

$1 \mathbf{b}$

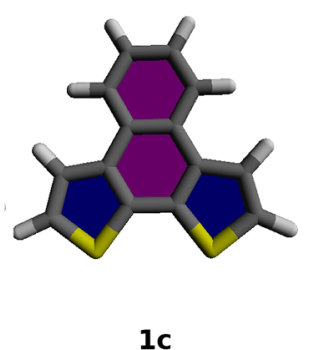

$1 \mathrm{C}$

Figure 4. Conformations of $\mathbf{1 a}, \mathbf{1 b}$, and $\mathbf{1 c}$ considered in the calculations of this work.

Table 1. Calculated Relative Free Energies for the 1a/1b/1c System $\left(\mathrm{kJ} \mathrm{mol}^{-1}\right)^{a}$

\begin{tabular}{lcccc}
\multicolumn{1}{c}{ method $^{b}$} & 1a-p & 1a-ap & 1b & 1c+ $\mathrm{H}_{2}$ \\
B3LYP & 70.6 & 72.1 & 183.3 & 0 \\
M06-2X & 61.6 & 64.0 & 186.6 & 0 \\
$\omega$ B97X-D & 53.2 & 55.0 & 177.9 & 0 \\
CAM-B3LYP & 55.4 & 56.8 & 177.2 & 0
\end{tabular}

${ }^{a}$ Energies given relative to the total free energy of the $1 \mathrm{c}+\mathrm{H}_{2}$ system.

${ }^{b}$ Geometry optimizations carried out using the cc-pVDZ basis set and singlepoint calculations carried out using the cc-pVTZ basis set, employing in both cases an SMD description of a MeCN solvent. being a Woodward-Hoffmann forbidden reaction. It is also notable that the electrocyclization transition structure (henceforth denoted TS) calculated by each method has substantial diradical character, which is another key characteristic of Woodward-Hoffmann forbidden reactions ${ }^{56-59}$ and is revealed by the nonzero $(\sim 0.7)$ expectation value of the spinsquared operator and the associated spin densities given in Table S2 of the SI.

As for the calculated relative free energies of $\mathbf{1 a}$-ap and $\mathbf{1 b}$, these predict that the overall electrocyclization process is endergonic by $111-123 \mathrm{~kJ} \mathrm{~mol}^{-1}$ (see Table 1), which is readily explained by the loss of aromaticity in the $\pi$-linker. Should the electrocyclization be inducible by sunlight, this 
Table 2. Calculated Free-Energy Barriers for the 1a-ap $\rightarrow 1 b$ Thermal Electrocyclization and the $1 \mathrm{~b} \rightarrow$ 1a-ap Thermal Cycloreversion of the Parent Switch 1a and Its Methylated Derivatives $\mathrm{Me}_{4}-\mathrm{a}, \mathrm{Me}_{2}-1 \mathrm{a}$, and $\mathrm{Me}_{2}-1 \mathrm{a} *\left(\mathrm{~kJ} \mathrm{~mol}^{-1}\right)^{a}$

\begin{tabular}{llcc} 
switch & \multicolumn{1}{c}{ method } & electrocyclization & cycloreversion \\
1a & B3LYP & 182.6 & 70.5 \\
1a & M06-2X & 197.0 & 76.0 \\
1a & $\omega$ B97X-D & 190.0 & 66.6 \\
1a & CAM-B3LYP & 190.3 & 68.8 \\
$\mathbf{M e}_{\mathbf{4}}-\mathbf{1 a}$ & $\omega$ B97X-D & 210.0 & 72.1 \\
$\mathbf{M e}_{2}-1 \mathbf{a}$ & $\omega$ B97X-D & 184.7 & 77.6 \\
$\mathbf{M e}_{2}-1 \mathbf{a}^{*}$ & $\omega$ B97X-D & 216.9 & 60.1
\end{tabular}

${ }^{a}$ All calculations were carried out using the aug-cc-pVTZ basis set and an SMD description of a MeCN solvent.

large endergonicity would be an attractive feature of systems of this kind for potential MOST applications. ${ }^{47-50}$ Such applications would also require that the free-energy barriers of $67-76 \mathrm{~kJ} \mathrm{~mol}^{-1}$ (see Table 2) that the calculations ascribe to the $\mathbf{1 b} \rightarrow \mathbf{1 a}$-ap thermal cycloreversion can be increased, so as to ensure that the absorbed solar energy can be stored for a long time. In order to briefly explore this possibility, cycloreversion barriers were also calculated for three methylated derivatives of the parent switch (see Scheme 3), including the aforementioned $\mathbf{M e}_{\mathbf{4}}-\mathbf{1 a}$ compound and two dimethylated compounds differing with respect to whether the methyls occur at the "outer" C9 and C15 positions $\left(\mathbf{M e}_{\mathbf{2}}-\mathbf{1 a}\right)$ or the ring-closing $\mathrm{C} 11$ and $\mathrm{C} 13$ positions $\left(\mathbf{M e}_{2}-\mathbf{1 a} *\right)$. Incorporated into Table 2, the results of these calculations suggest that the $\mathrm{C} 9$ and $\mathrm{C} 15$ methyls increase the barrier by 11 $\mathrm{kJ} \mathrm{mol}^{-1}$, whereas the $\mathrm{C} 11$ and $\mathrm{C} 13$ methyls decrease it by $7 \mathrm{~kJ}$ $\mathrm{mol}^{-1}$. Accordingly, in $\mathbf{M e}_{4}-\mathbf{1 a}$, the two effects add up to a slight increase of the barrier relative to the parent switch. Interestingly, this indicates that the absence noted in section 2.1 of a change in the experimental absorption spectrum of $\mathbf{M e}_{4}$-1a upon irradiation with UV-light, is not related to the influence of the C11 and C13 methyls on the cycloreversion, but rather to their ability to prevent oxidation of the ringclosed species. $^{53}$
Turning thus to the oxidation of $\mathbf{1 b}$ by atmospheric $\mathrm{O}_{2}$, which yields $\mathbf{1 c}$ and $\mathrm{H}_{2} \mathrm{O}$, the calculated free energies in Table S3 of the SI suggest that this reaction proceeds with an astoundingly large exergonicity $\left(\Delta G_{2}\right)$ of $400-420 \mathrm{~kJ} \mathrm{~mol}^{-1}$. Thereby, the experimental detection of $1 \mathrm{c}$ described in section 2.1 can be rationalized by the fact that the driving force for oxidation is much larger than the driving force for thermal cycloreversion (111-123 kJ mol ${ }^{-1}$ ). Moreover, the driving force for oxidation can be partitioned into two components: the first $\left(\Delta G_{3}\right)$ being associated with the formation of $\mathrm{H}_{2} \mathrm{O}$ from $\mathrm{H}_{2}$ and $\mathrm{O}_{2}$, and the second $\left(\Delta G_{2}-\Delta G_{3}\right)$ reflecting the gain in aromaticity upon formation of the central sixmembered ring that fuses the two thienyls in 1c (see Scheme $2)$. As can be seen from Table S3, these two components amount to $217-233$ and $177-187 \mathrm{~kJ} \mathrm{~mol}^{-1}$, respectively.

2.3. Calculated UV-vis Absorption Spectra. The second task for the computational part of this work is to assess how well the TD-DFT methodology adopted for the modeling of the photocyclization of $\mathbf{1 a}$ reproduces the experimental UV-vis absorption spectrum of this compound in $\mathrm{MeCN}$ solution. To this end, the absorption of 1a-p and 1aap was calculated with the same four DFT methods employed for the modeling of the thermal processes discussed in section 2.2. Again, an $\mathrm{SMD}^{55}$ description of the $\mathrm{MeCN}$ solvent was used, in combination with the cc-pVTZ basis set. For each species, vertical excitation energies from the ground state $\left(S_{0}\right)$ to the ten lowest singlet excited states and the associated oscillator strengths were calculated to derive, through convolution with Gaussian functions with the full width at half-maximum set to $0.5 \mathrm{eV}$, the UV-vis absorption spectra shown in Figure 5a. In addition, "total" spectra of 1a-p and 1aap were derived by assuming the individual contributions of 1a-p and 1a-ap to be quantifiable in terms of their Boltzmann weights. The corresponding spectra are given in Figure $5 b$, which also includes the experimental spectrum of 1 a for comparison.

As can be inferred from the excitation energies and oscillator strengths summarized in Table S4 of the SI, the high-energy band in the spectra of both 1a-p and 1a-ap in Figure 5a calculated with the M06-2X, $\omega$ B97X-D and CAM-B3LYP methods is dominated by the $S_{0} \rightarrow S_{3}$ transition, which occurs
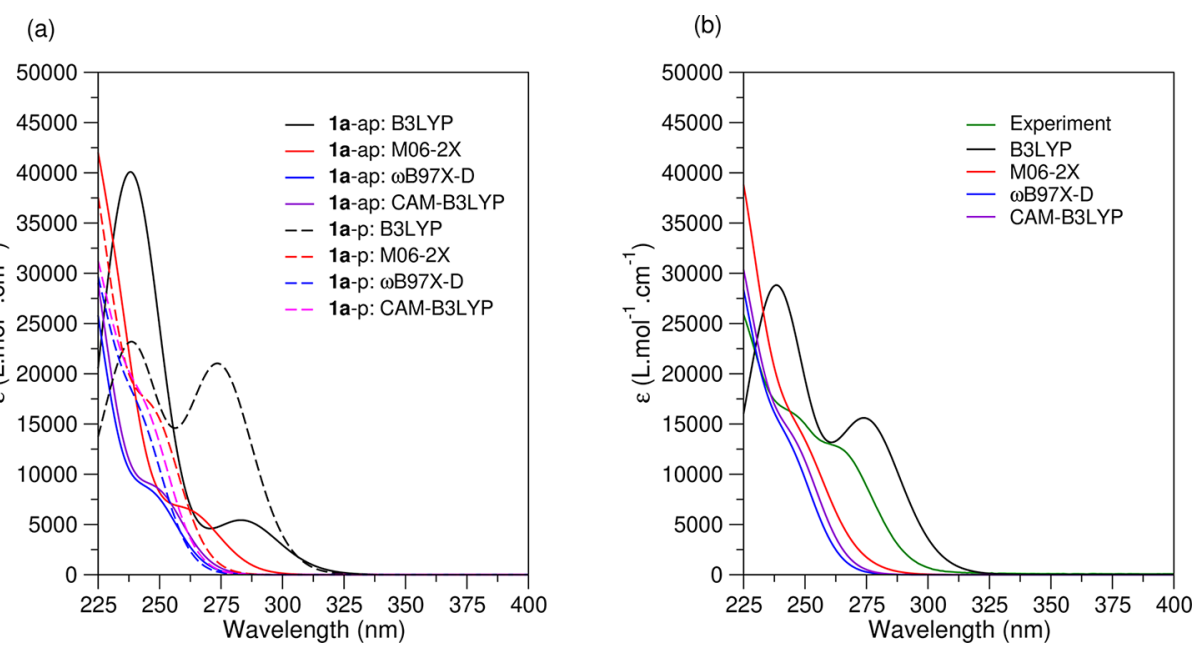

Figure 5. (a) UV-vis absorption spectra of 1a-p and 1a-ap in MeCN solution calculated with different DFT methods. (b) Boltzmann-weighted UV-vis absorption spectra of 1a-p and 1a-ap in MeCN solution calculated with different DFT methods and compared with the experimental spectrum of 1a. 
(a)

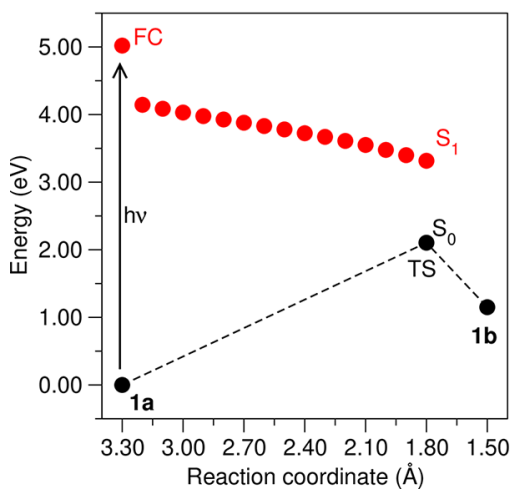

(b)

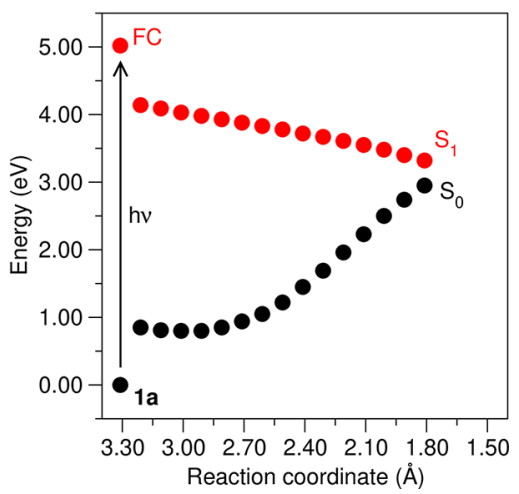

Figure 6. (a) Calculated $S_{1}$ photocyclization path of $1 \mathbf{a}$ and relative energies of $\mathbf{1 a}, \mathbf{1} \mathbf{b}$, and the TS geometry along the thermal $S_{0}$ electrocyclization path. (b) Calculated $S_{1}$ photocyclization path of $1 \mathrm{a}$ and $S_{0}$ energies at the corresponding geometries.

(a)

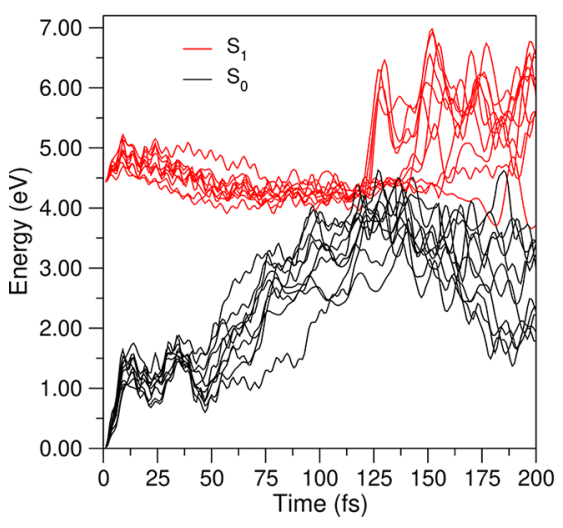

(b)

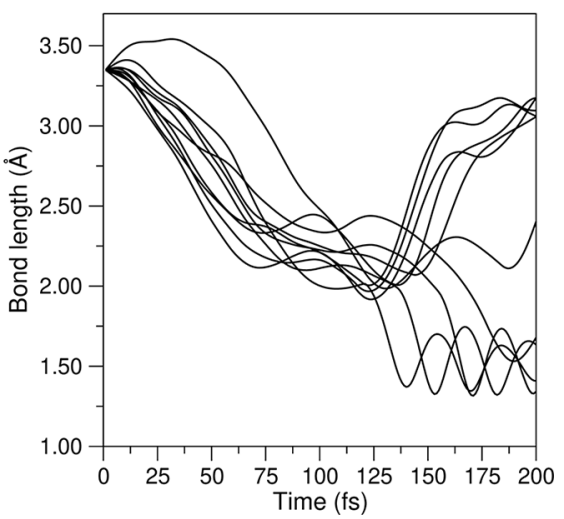

Figure 7. Changes in $S_{1}$ and $S_{0}$ energies (a) and C11-C13 bond length (b) during the ten NAMD trajectories run for 1a.

at $\sim 5.5 \mathrm{eV} / \sim 225 \mathrm{~nm}$. Furthermore, the absorption shoulder at $\sim 250 \mathrm{~nm}$ predicted by these methods can be assigned to the $S_{0}$ $\rightarrow S_{1} \pi \pi^{*}$ transition, which is located at 4.84-5.09 eV/244$256 \mathrm{~nm}$ (at the B3LYP level, this transition results in a clearly identifiable lower-energy band). From Figure S13 of the SI, it can be seen that the frontier $\pi$-molecular orbitals involved in the $S_{0} \rightarrow S_{1}$ transition are primarily localized on the benzene $\pi$ linker, with negligible contributions from the atoms of the two thienyls. This suggests that it is indeed this moiety, and not the thienyls, whose aromaticity may influence the photocyclization of 1 a.

Turning to the Boltzmann-weighted total spectra in Figure 5 b, especially M06-2X, $\omega$ B97X-D and CAM-B3LYP achieve good overall agreement with the experimental spectrum of $\mathbf{1 a}$. Furthermore, given that the ${ }^{1} \mathrm{H}$ NMR analysis in section 2.1 attributed the appearance in Figure 2 of new near-UV absorption bands upon irradiation of 1 a at $254 \mathrm{~nm}$ to the formation of $\mathbf{1 c}$, it is also gratifying that the lower-energy band in the calculated spectra of 1 c (see Figure S14b of the SI) is indeed red-shifted relative to those in the calculated spectra of 1a-p and 1a-ap (see Figure 5a). Overall, then, we believe that the results in Figures 5 and S14b lend credence to the use of TD-DFT for the modeling of the photocyclization of $\mathbf{1 a}$, which we turn to next. Since 1a-ap, but not 1a-p, undergoes photocyclization, ${ }^{33,34}$ all calculations pertaining to compound 1a described henceforth were carried out using strictly the 1aap species, which is hereafter referred to as simply $\mathbf{1 a}$.
2.4. Photocyclization. The results from the modeling of the $1 \mathrm{a} \rightarrow \mathbf{1 b}$ photocyclization in the $S_{1}$ state through static TD-DFT calculations with the $\omega$ B97X-D method are summarized in Figure 6, which for comparison also includes results relevant for the symmetry-forbidden thermal electrocyclization reaction. For example, as was already noted in Table 2, it can be seen that the thermal reaction is prohibited by a very large barrier. Contrarily, following light absorption and population of the vertically excited $S_{1}$ FC point of 1a, Figure $6 \mathrm{a}$ shows that photocyclization along the $\mathrm{C} 11-\mathrm{C} 13$ (see Scheme 2) reaction coordinate proceeds in a completely barrierless fashion, whereby the $S_{1}$ and $S_{0}$ states approach degeneracy (see Figure $6 b$ ) in the region of a presumed $S_{1} / S_{0}$ conical intersection (CI) seam. The excited-state evolution toward this seam, which affords a decay channel to the $S_{0}$ state, is driven by a large decrease in $S_{1}$ energy relative to the FC point at $\mathrm{C} 11-\mathrm{C} 13=3.29 \AA$. For example, at $\mathrm{C} 11-\mathrm{C} 13=1.80$ $\AA$, the decrease in $S_{1}$ energy amounts to $1.70 \mathrm{eV}$. In order to corroborate this result in light of potential problems in the treatment of static correlation effects by TD-DFT, ${ }^{60}$ singlepoint calculations carried out with the complete active space second-order perturbation theory (CASPT2) method ${ }^{61,62}$ yield a value of very similar magnitude $(1.74 \mathrm{eV}$, see Table $\mathrm{S} 6$ of the $\mathrm{SI})$. Furthermore, based on the observation that $\mathbf{1 b}$ is produced by a $\omega$ B97X-D $S_{0}$ geometry optimization started in the vicinity of the presumed $S_{1} / S_{0}$ CI seam at $\mathrm{C} 11-\mathrm{C} 13=$ $1.80 \AA$, it also seems plausible that $\mathbf{1 b}$ is indeed the $S_{0}$ photoproduct of the photocyclization of $1 \mathrm{a}$. 
(a)

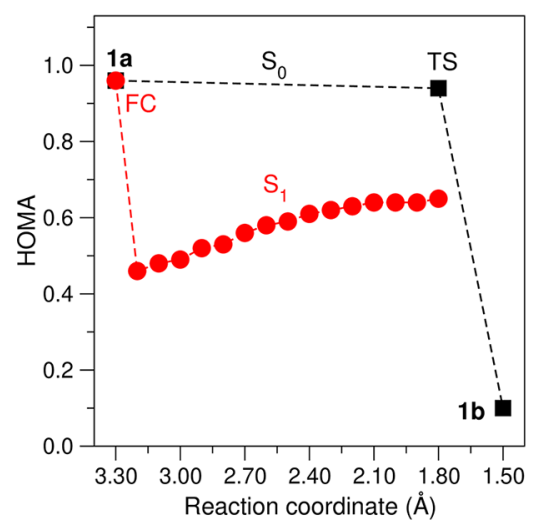

(b)

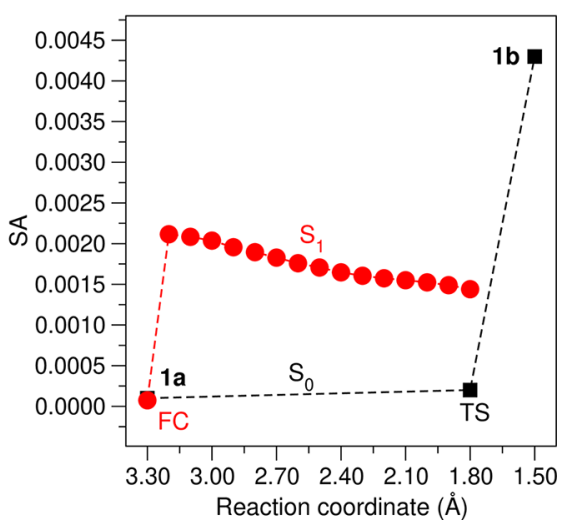

Figure 8. Changes in HOMA (a) and SA values (b) for the benzene $\pi$-linker along the $S_{1}$ photocyclization path of 1a. Also shown are the HOMA and $S A$ values for $\mathbf{1 a}, \mathbf{1 b}$, and the TS geometry along the thermal $S_{0}$ electrocyclization path.

It should be noted that even though the calculations summarized in Figure 6 suggest that the $\mathbf{1 a} \rightarrow \mathbf{1 b}$ photocyclization is a favorable reaction, the underlying procedure to perform $S_{1}$ geometry optimizations along a predefined $\mathrm{C} 11-\mathrm{C} 13$ reaction coordinate neither accounts for possible competition from other reactions, nor provides an estimate of the time scale for the overall photocyclization process. In order to address these issues, we also carried out nonadiabatic molecular dynamics (NAMD) simulations ${ }^{63-67}$ with Tully's fewest switches algorithm ${ }^{68}$ at the level of B3LYP for the DFT and TD-DFT parts. These simulations, which describe the simultaneous evolution of the electronic and nuclear degrees of freedom of the photoswitch, were started from the $S_{1}$ FC point of $1 \mathrm{a}$ and were run for maximally $200 \mathrm{fs}$ with ten different initial nuclear velocities generated randomly from a Maxwell-Boltzmann distribution at $300 \mathrm{~K}$. The key results are summarized in Figure 7.

As can be seen from Figure $7 \mathrm{a}$, there is an apparent tendency for the excited-state dynamics to allow the $S_{1}$ and $S_{0}$ states to approach degeneracy, and to do so very quickly (within $\sim 100$ fs in many trajectories). Furthermore, it is clear from the rapid decrease in $\mathrm{C} 11-\mathrm{C} 13$ distance observed in all ten trajectories (see Figure $7 \mathrm{~b}$ ) that a key component of the dynamics is indeed ring-closing along the $\mathrm{C} 11-\mathrm{C} 13$ coordinate. In fact, within $200 \mathrm{fs}$, four out of ten trajectories oscillate around a C11-C13 distance of $1.5 \AA$. Since all ten trajectories are evolving in the $S_{0}$ state at that stage (see Figure S15 of the SI), this means that $40 \%$ of the trajectories have completed the reaction and formed the $\mathbf{1 b}$ photoproduct within $200 \mathrm{fs}$. Thus, the $\mathbf{1 a} \rightarrow \mathbf{1 b}$ photocyclization appears to be very fast and not much impeded by competing processes. Loosely, this $200 \mathrm{fs}$ time scale is consistent with findings reported in time-resolved spectroscopic studies of ring-closing in diarylethene switches. ${ }^{69-72}$ Finally, on a technical note, complementary NAMD simulations reported in Figures S16 and S17 of the SI performed with initial nuclear velocities generated at $500 \mathrm{~K}$ instead of $300 \mathrm{~K}$, give results similar to those just described.

2.5. Aromaticity Indices. Having obtained computational evidence that the $\mathbf{1 a} \rightarrow \mathbf{1 b}$ photocyclization is an ultrafast and efficient reaction, we now set out to investigate if this finding can be rationalized in terms of photoinduced changes in aromaticity of the benzene $\pi$-linker. To this end, aromaticity indices of four different types-geometric, electronic, magnetic, and energetic-were calculated for this moiety. Starting with the geometric harmonic oscillator model of aromaticity (HOMA) index, ${ }^{73,74}$ which probes the deviation of carboncarbon bond lengths from an ideal aromatic reference value for benzene, aromatic and nonaromatic systems usually exhibit HOMA values close to 1 and 0 , respectively. ${ }^{73-75}$ Presenting the HOMA values of $\mathbf{1 a}$ and $\mathbf{1 b}$ in the $S_{0}$ state calculated from the corresponding $\omega$ B97X-D geometries, as well as the HOMA values along the $S_{1}$ photocyclization path of 1 a calculated based on the corresponding TD- $\omega$ B97X-D geometries, Figure 8 a unsurprisingly shows that $\mathbf{1 a}(0.96)$ and $\mathbf{1 b}(0.10)$ are typical $S_{0}$ aromatic and nonaromatic systems, respectively. However, more interestingly, as the photoexcited system evolves from the $S_{1}$ FC point of 1a, the HOMA values are much reduced (from 0.96 to $0.46-0.65$ ), which suggests that there is a loss of aromaticity in the $S_{1}$ state relative to the $S_{0}$ state that might contribute to the photocyclization reactivity of 1a.

Continuing with the electronic Shannon aromaticity (SA) index, ${ }^{76,77}$ which is formulated in the framework of Bader's theory of atoms in molecules ${ }^{78}$ and measures the variation in electron density at bond critical points, the analysis of these results in Figure $8 \mathrm{~b}$ (obtained from $S_{0}$ and $S_{1}$ electron densities calculated with $\omega$ B97X-D and TD- $\omega$ B97X-D, respectively) supports the same conclusion as the analysis of the HOMA values in Figure 8a. Specifically, noting that aromatic systems typically show smaller SA values than their nonaromatic analogues because of their more uniform distribution of electron density, ${ }^{76,77}$ the SA values are increased from 0.0001 for $1 \mathrm{a}$ in the $S_{0}$ state to $0.0014-0.0021$ along the $S_{1}$ photocyclization path.

Despite the agreement between the HOMA and SA values, it is important to point out that these indices do not distinguish between nonaromaticity and antiaromaticity. Moreover, as can be inferred from Figure 8, they are not able to probe changes in aromaticity during the photoexcitation from the $S_{0}$ state of $\mathbf{1 a}$ to the $S_{1} \mathrm{FC}$ point. In order to circumvent these limitations, the aromaticity of the benzene $\pi$-linker in the $S_{0}$ and $S_{1}$ states of 1a was assessed magnetically through calculation of nucleusindependent chemical shift (NICS) indices ${ }^{79,80}$ by means of a NICS-scan procedure. ${ }^{81,82}$ These indices probe ring currents induced by circulating $\pi$-electrons, and were calculated from wave functions obtained with the complete active space selfconsistent field (CASSCF) method $^{83}$ and using gaugeincluding atomic orbitals. 
The results of this investigation are summarized in Figure 9. We see that the $S_{0}$ state of 1a shows negative NICS values

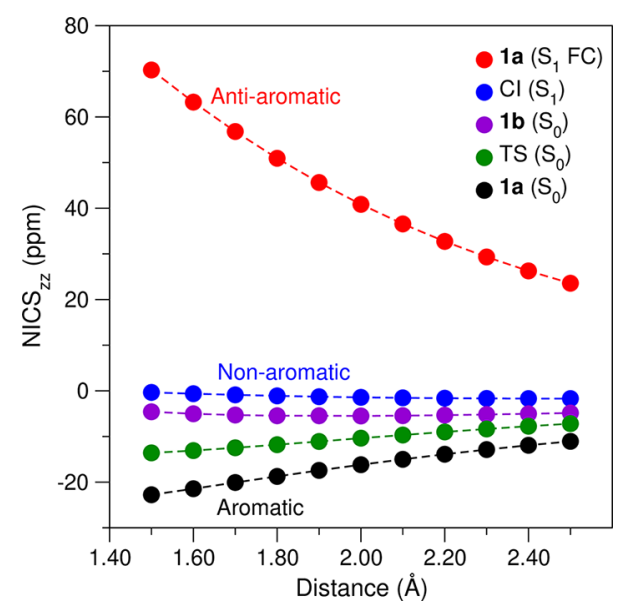

Figure 9. NICS $\mathrm{S}_{z z}$-scan values for the benzene $\pi$-linker in the $S_{0}$ state and at the $S_{1}$ FC point of 1a. These values are denoted $1 \mathbf{a}\left(S_{0}\right)$ and 1a $\left(S_{1} \mathrm{FC}\right)$, respectively. Also shown are the $\mathrm{NICS}_{\mathrm{zz}}$-scan values for a structure in the CI region (at $\mathrm{C} 11-\mathrm{C} 13=1.80 \AA$ ) along the $\mathrm{S}_{1}$ photocyclization path of 1a, for the TS geometry along the thermal $S_{0}$ electrocyclization path of $\mathbf{1 a}$, and for the $S_{0}$ state of $\mathbf{1 b}$. These values are denoted CI $\left(S_{1}\right)$, TS $\left(S_{0}\right)$, and $\mathbf{1 b}\left(S_{0}\right)$, respectively.

between -11 and $-22 \mathrm{ppm}$, indicating diatropic ring currents or aromaticity. ${ }^{79}$ At the $S_{1} \mathrm{FC}$ point, on the other hand, the NICS values are positive $(23-70 \mathrm{ppm})$, suggesting paratropic ring currents or antiaromaticity. ${ }^{79}$ In the CI region along the $S_{1}$ photocyclization path, in turn, the NICS values are close to zero, reflecting the absence of ring currents or nonaromaticity. ${ }^{79}$ Accordingly, the overall picture that emerges from Figure 9 regarding changes in aromaticity during the course of the photocyclization of $\mathbf{1 a}$, is that the $\pi$-linker goes from being aromatic in the $S_{0}$ state to antiaromatic at the $S_{1}$ FC point, and then turns nonaromatic in the CI region. Thereby, it appears that the photocyclization is driven by the loss of aromaticity and the concurrent formation of a reactive, antiaromatic excited state from the initial photoexcitation, and by the subsequent relief of this antiaromaticity as the reaction progresses from the FC point. In other words, the reaction is facilitated by photoinduced changes in aromaticity.

In order to quantify in energetic terms the loss of aromaticity during photoexcitation and the loss of antiaromaticity during the excited-state evolution, two novel aromaticity indices were introduced and calculated for a methylated (at the benzene motif) derivative of $\mathbf{1 a}$ and its nonaromatic exocyclic methylene isomer. Denoted 2 and 2-ref, respectively, these compounds are shown in Scheme 3. The indices in question, which are reminiscent of the isomerization stabilization energy (ISE) aromaticity index ${ }^{84}$ quantify the difference $\triangle \mathrm{VEE}=$ $\operatorname{VEE}(2)-\operatorname{VEE}\left(2\right.$-ref) in the vertical $S_{0} \rightarrow S_{1}$ excitation energies of $\mathbf{2}$ and 2-ref, and the difference $\triangle \mathrm{FCRE}=\mathrm{FCRE}(\mathbf{2})$ - FCRE(2-ref) in the $S_{1} F C$ relaxation energies of $\mathbf{2}$ and 2-ref (the $S_{1} F C$ relaxation energy is the decrease in $S_{1}$ energy from the FC point to the minimum on the $S_{1}$ PES). Thereby, if there is a distinct loss of aromaticity during the photoexcitation of 1a and similarly a pronounced loss of antiaromaticity during its subsequent excited-state evolution, one expects these indices to be positive and large. Thus, it is encouraging to note from calculations presented in Table S7 of the SI that this is indeed the case, with $\triangle \mathrm{VEE}$ and $\triangle \mathrm{FCRE}$ amounting to 1.11 and $0.71 \mathrm{eV}$, respectively. This finding is consistent with a previous study on cyclopentadienes and siloles demonstrating that aromatic compounds have relatively larger vertical excitation energies than their nonaromatic or antiaromatic analogues. 85

Finally, we note that it is of interest for future studies to explore how functionalization of the benzene motif with different electronic substituents might influence the photoinduced changes in aromaticity. In this regard, the attachment of strongly electron-withdrawing groups to benzene has previously been found to reverse the character of its $T_{1}$ state from antiaromatic to aromatic. ${ }^{18}$ As a brief investigation of this issue, $\triangle \mathrm{VEE}$ and $\triangle \mathrm{FCRE}$ values were also calculated for a derivative of $\mathbf{2}$ (denoted $\mathbf{3}$ in Scheme 3) featuring an electronwithdrawing nitro group at the benzene motif. Interestingly, the $\triangle \mathrm{VEE}$ and $\triangle \mathrm{FCRE}$ values of 0.82 and $0.36 \mathrm{eV}$ for this compound given in Table S7 are noticeably smaller than those of 1.11 and $0.71 \mathrm{eV}$ calculated for 2 . Hence, the nitro group appears to inhibit the photoinduced changes in aromaticity.

\section{CONCLUSIONS}

We have synthesized dithienylbenzene $1 \mathrm{a}$ and reported ${ }^{1} \mathrm{H}$ NMR evidence that this compound undergoes electrocyclization upon irradiation with UV-light of $254 \mathrm{~nm}$. Furthermore, through a detailed computational analysis, we have found that the electrocyclization process is facilitated by photoinduced changes in the aromaticity of the benzene motif of 1a. More specifically, there is a loss of aromaticity during the initial photoexcitation that produces a reactive, antiaromatic excited state (NICS values change from distinctly negative to distinctly positive), and subsequently a relief of this antiaromaticity as the photoexcited system evolves from the FC point toward the CI seam (NICS values change from distinctly positive to $\sim$ zero). Through NAMD simulations, this evolution is predicted to be very fast $(\sim 100 \mathrm{fs})$ and to be followed by excited-state decay and complete electrocyclization within 200 fs in many (40\%) of the simulated trajectories. Altogether, the results of this work show that the concept of ESA holds substantial promise as a tool for designing potent electrocyclization-based photoswitches within the framework of dithienylethenes. In future research, we plan to investigate whether this concept is fruitfully applicable also to the design of photoswitches based on other reactions and frameworks.

\section{EXPERIMENTAL AND COMPUTATIONAL DETAILS}

4.1. Synthesis. Dithienylbenzene 1a was synthesized in a single step via a 2 -fold Suzuki-Miyaura cross-coupling of 1,2-dibromobenzene and 3-thienylboronic acid in excellent yield (see Scheme 4). Full details are given in the SI.

4.2. UV-vis Absorption and ${ }^{1} \mathrm{H}$ NMR Spectroscopy. Full details are given in the SI.

Scheme 4. Synthesis of 1a

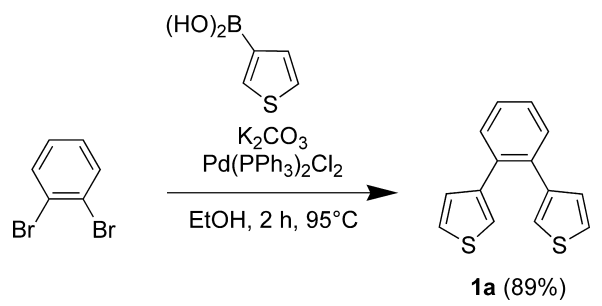


4.3. Quantum Chemical Calculations. Thermal and photochemical reactions were modeled using DFT and TD-DFT, ${ }^{86-94}$ respectively. As for the former reactions, $S_{0}$ stationary points corresponding to $\mathbf{1 a}, \mathbf{1 b}, \mathbf{1} \mathbf{c}$, and the electrocyclization transition structure (TS) connecting $\mathbf{1 a}$ and $\mathbf{1 b}$ were located by performing geometry optimizations using the B3LYP, ${ }^{95,96}$ M06-2X, ${ }^{97,98} \omega \mathrm{B} 97 \mathrm{X}-$ $\mathrm{D},{ }^{99}$ and CAM-B3LYP ${ }^{100}$ hybrid density functionals in combination with the cc-pVDZ basis set (in some cases also with the larger aug-ccpVTZ basis set). For each structure optimized at a specific level of theory, frequency calculations were carried out at that level to obtain Gibbs free energies at room temperature and to ensure that the structure in question is either a minimum with real vibrational frequencies only (1a, $\mathbf{1 b}$, and $\mathbf{1 c}$ ), or a first-order saddle point with one imaginary vibrational frequency (TS). In order to refine the electronic contribution to the free energies, the geometries obtained with a specific functional were subjected to singlepoint calculations with that functional and the larger triple- $\xi$ cc-pVTZ basis set. All calculations were performed using an $\mathrm{SMD}^{55}$ continuum solvation model representation of a $\mathrm{MeCN}$ solvent.

As for the TD-DFT modeling of the $\mathbf{1 a} \rightarrow \mathbf{1 b}$ photocyclization, in turn, this was done within the Tamm-Dancoff approximation (TDA $)^{101-104}$ to TD-DFT using exclusively the $\omega$ B97X-D functional. This choice was made in part because $\omega \mathrm{B} 97 \mathrm{X}-\mathrm{D}$ is a range-separated hybrid functional, which has proven a useful feature for the description of photoisomerization reactions, ${ }^{105,106}$ and in part because $\omega \mathrm{B} 97 \mathrm{X}-\mathrm{D}$ includes empirical $1 / R^{6}$ atom-atom dispersion corrections ${ }^{99,107,108}$ suitable for capturing weak intermolecular interactions between the two thienyl units. Starting from the $\omega$ B97X-D/cc-pVDZ $\mathrm{S}_{0}$ geometry of $1 \mathrm{a}$, whose $\mathrm{C} 11-\mathrm{C} 13$ distance is $3.29 \AA$, the $\mathrm{S}_{1}$ photocyclization path was computed by first locating the vertically excited $S_{1} F C$ point through a singlepoint calculation with the ccpVTZ basis set and the SMD ( $\mathrm{MeCN})$ model. Subsequently, additional points along the path were obtained by performing a series of constrained $S_{1}$ geometry optimizations (again with the ccpVDZ basis set) in which the $\mathrm{C} 11-\mathrm{C} 13$ distance was varied between 3.20 and $1.80 \AA$ in steps of $0.10 \AA$. In each optimization, all other geometric degrees of freedom than the $\mathrm{C} 11-\mathrm{C} 13$ distance were allowed to relax. For computational expedience, the optimizations were done in the gas phase, but were followed by singlepoint calculations (again with the cc-pVTZ basis set) utilizing the SMD $(\mathrm{MeCN})$ model. Finally, as a complement to the TD-DFT modeling, singlepoint calculations along the $S_{1}$ photocyclization path were also carried out with the CASPT2 method, ${ }^{61,62}$ as further detailed in the SI.

4.4. NAMD Simulations. The NAMD simulations were done with the implementation of Tully's fewest switches algorithm ${ }^{68}$ in TURBOMOLE ${ }^{64,109}$ at the B3LYP/cc-pVDZ level of theory for the DFT and TD-DFT parts. The reason for using B3LYP, and not $\omega \mathrm{B} 97 \mathrm{X}-\mathrm{D}$, is that the latter method is not implemented in TURBOMOLE. The simulations were started from the $S_{1} F C$ point of $1 \mathrm{a}$ and were run for maximally $200 \mathrm{fs}$ with two sets of ten different initial nuclear velocities generated randomly from a MaxwellBoltzmann distribution at 300 and $500 \mathrm{~K}$, respectively. The exact criteria used to enforce a hop between the $S_{1}$ and $S_{0}$ states in the simulations are given in the SI.

4.5. Aromaticity Indices and Software Used. Full details on the calculations of HOMA, ${ }^{73,74} \mathrm{SA}^{76,77}$ and NICS ${ }^{79-82}$ indices for the benzene $\pi$-linker are given in the SI. Briefly, HOMA values were calculated based on $\mathrm{S}_{0}$ and $\mathrm{S}_{1}$ geometries optimized at the $\omega \mathrm{B} 97 \mathrm{X}-\mathrm{D} /$ cc-pVDZ and TD- $\omega$ B97X-D/cc-pVDZ levels of theory, respectively. $S A$ values, in turn, were derived from $S_{0}$ and $S_{1}$ electron densities computed at the $\omega$ B97X-D/cc-pVTZ and TD- $\omega$ B97X-D/cc-pVTZ levels of theory, respectively. NICS $\mathrm{ZZ}_{\mathrm{ZZ}}$ values, ${ }^{80}$ finally, were calculated following a NICS-scan procedure ${ }^{81,82}$ using $S_{0}$ and $S_{1}$ wave functions obtained at the CASSCF/cc-pVDZ level of theory. More specifically, NICS values were calculated along the axis passing through the geometric center of the $\pi$-linker at distances above the center ranging from 1.50 to $2.50 \AA$ in steps of $0.10 \AA$. This procedure is designed to avoid the undesirable arbitrariness associated with NICS-index calculations that only consider one single point in space. ${ }^{81,82,110}$
The calculations were done with the Gaussian $16,{ }^{111}$ OpenMolcas 18.09, ${ }^{112}$ TURBOMOLE 7.4, ${ }^{109,113}$ Dalton2016.2, ${ }^{114,115}$ and Mul$\operatorname{tiwfn}^{116}$ programs. Gaussian 16 was used for DFT and TD-DFT calculations. OpenMolcas 18.09 was used for CASSCF and CASPT2 calculations. TURBOMOLE 7.4 was used for NAMD simulations. Dalton2016.2 was used for NICS-index calculations. Multiwfn was used for HOMA- and SA-index calculations.

\section{ASSOCIATED CONTENT}

\section{Supporting Information}

The Supporting Information is available free of charge at https://pubs.acs.org/doi/10.1021/jacs.0c06327.

Description of general experimental procedures; description of the synthesis of compounds 1a (Scheme S1) and $\mathbf{M e}_{4}$-1a (Scheme S2); complementary experimental UV-vis absorption spectra (Figures S1-S5); ${ }^{1} \mathrm{H}$ NMR characterization of the photochemical ring-closing and oxidation of compound 1a (Scheme S3 and Figures S6S8); NMR spectra of the reported compounds (Figures S9-S12); complementary computational details; complementary computational results (Figures S13-S17 and Tables S1-S7); description of multimedia file; and Cartesian coordinates for optimized $S_{0}$ and $S_{1}$ geometries (PDF)

Multimedia file with an animation of a representative trajectory from the NAMD simulations describing a successful $\mathbf{1 a} \rightarrow \mathbf{1 b}$ photocyclization event (MP4)

\section{AUTHOR INFORMATION}

\section{Corresponding Authors}

Baswanth Oruganti - Department of Chemistry and Biomedical Sciences, Faculty of Health and Life Sciences, Linnaeus University, SE-45041 Kalmar, Sweden; 이이.org/0000-

0002-4199-2750; Email: baswanth.oruganti@lnu.se

Gábor London - MTA-TTK "Lendület" Functional Organic Materials Research Group, Institute of Organic Chemistry, Research Centre for Natural Sciences, 1117 Budapest, Hungary; ○ orcid.org/0000-0001-6078-3180; Email: london.gabor@ttk.hu

Bo Durbeej - Division of Theoretical Chemistry, IFM, Linköping University, SE-58183 Linköping, Sweden; ○ orcid.org/0000-0001-5847-1196; Email: bodur@ifm.liu.se

\section{Authors}

Péter Pál Kalapos - MTA-TTK "Lendület" Functional Organic Materials Research Group, Institute of Organic Chemistry, Research Centre for Natural Sciences, 1117 Budapest, Hungary

Varada Bhargav - Department of Chemistry, GITAM Institute of Science, GITAM (deemed to be University), Visakhapatnam 530045, Andhra Pradesh, India; (i) orcid.org/0000-0001$7046-4140$

Complete contact information is available at: https://pubs.acs.org/10.1021/jacs.0c06327

\section{Notes}

The authors declare no competing financial interest.

\section{ACKNOWLEDGMENTS}

B.D. acknowledges financial support by the Olle Engkvist Foundation (Grant Nos. 184-568 and 204-0183) and the Swedish Research Council (Grant No. 2019-03664), and grants of computing time at the National Supercomputer Centre (NSC) in Linköping, Sweden. G.L. acknowledges 
financial support by the Hungarian Academy of Sciences through the Lendület Program (LENDULET_2018_355) and the National Research, Development and Innovation Office, Hungary (NKFIH Grant No. FK 123760).

\section{REFERENCES}

(1) Dewar, M. J. S. A Molecular Orbital Theory of Organic Chemistry-VIII. Aromaticity and Electrocyclic Reactions. Tetrahedron 1966, 22, 75-92.

(2) Zimmerman, H. E. On Molecular Orbital Correlation Diagrams, the Occurrence of Möbius Systems in Cyclization Reactions, and Factors Controlling Ground- and Excited-State Reactions. I. J. Am. Chem. Soc. 1966, 88, 1564-1565.

(3) Schleyer, P. v. R.; Wu, J. I.; Cossio, F. P.; Fernández, I. Aromaticity in Transition Structures. Chem. Soc. Rev. 2014, 43, 49094921.

(4) Clarke, J.; Fowler, P. W.; Gronert, S.; Keeffe, J. R. Effect of Ring Size and Migratory Groups on $[1, n]$ Suprafacial Shift Reactions. Confirmation of Aromatic and Antiaromatic Transition-State Character by Ring-Current Analysis. J. Org. Chem. 2016, 81, 87778788.

(5) Gilmore, K.; Manoharan, M.; Wu, J. I.-C.; Schleyer, P. v. R.; Alabugin, I. V. Aromatic Transition States in Nonpericyclic Reactions: Anionic 5-Endo Cyclizations Are Aborted Sigmatropic Shifts. J. Am. Chem. Soc. 2012, 134, 10584-10594.

(6) Chen, D.; Zhuang, D.; Zhao, Y.; Xie, Q.; Zhu, J. Reaction Mechanisms of Iron(III) Catalyzed Carbonyl-Olefin Metatheses in 2,5- and 3,5-Hexadienals: Significant Substituent and Aromaticity Effects. Org. Chem. Front. 2019, 6, 3917-3924.

(7) Baird, N. C. Quantum Organic Photochemistry. II. Resonance and Aromaticity in the Lowest ${ }^{3} \pi \pi^{*}$ State of Cyclic Hydrocarbons. J. Am. Chem. Soc. 1972, 94, 4941-4948.

(8) Aihara, J. Aromaticity-Based Theory of Pericyclic Reactions. Bull. Chem. Soc. Jpn. 1978, 51, 1788-1792.

(9) Karadakov, P. B. Ground- and Excited-State Aromaticity and Antiaromaticity in Benzene and Cyclobutadiene. J. Phys. Chem. A 2008, 112, 7303-7309.

(10) Karadakov, P. B. Aromaticity and Antiaromaticity in the LowLying Electronic States of Cyclooctatetraene. J. Phys. Chem. A 2008, 112, 12707-12713.

(11) Sung, Y. M.; Oh, J.; Kim, W.; Mori, H.; Osuka, A.; Kim, D. Switching between Aromatic and Antiaromatic 1,3-PhenyleneStrapped [26]- and [28] Hexaphyrins upon Passage to the Singlet Excited State. J. Am. Chem. Soc. 2015, 137, 11856-11859.

(12) Sung, Y. M.; Yoon, M.-C.; Lim, J. M.; Rath, H.; Naoda, K.; Osuka, A.; Kim, D. Reversal of Hückel (Anti)Aromaticity in the Lowest Triplet States of Hexaphyrins and Spectroscopic Evidence for Baird's Rule. Nat. Chem. 2015, 7, 418-422.

(13) Sung, Y. M.; Oh, J.; Naoda, K.; Lee, T.; Kim, W.; Lim, M.; Osuka, A.; Kim, D. A Description of Vibrational Modes in Hexaphyrins: Understanding the Aromaticity Reversal in the Lowest Triplet State. Angew. Chem. 2016, 128, 12109-12113.

(14) Oh, J.; Sung, Y. M.; Hong, Y.; Kim, D. Spectroscopic Diagnosis of Excited-State Aromaticity: Capturing Electronic Structures and Conformations upon Aromaticity Reversal. Acc. Chem. Res. 2018, 51, 1349-1358.

(15) Mohamed, R. K.; Mondal, S.; Jorner, K.; Delgado, T. F.; Lobodin, V. V.; Ottosson, H.; Alabugin, I. V. The Missing $\mathrm{C}_{1}-\mathrm{C}_{5}$ Cycloaromatization Reaction: Triplet State Antiaromaticity Relief and Self-Terminating Photorelease of Formaldehyde for Synthesis of Fulvenes from Enynes. J. Am. Chem. Soc. 2015, 137, 15441-15450.

(16) Papadakis, R.; Li, H.; Bergman, J.; Lundstedt, A.; Jorner, K.; Ayub, R.; Haldar, S.; Jahn, B. O.; Denisova, A.; Zietz, B.; Lindh, R.; Sanyal, B.; Grennberg, H.; Leifer, K.; Ottosson, H. Metal-Free Photochemical Silylations and Transfer Hydrogenations of Benzenoid Hydrocarbons and Graphene. Nat. Commun. 2016, 7, 12692.

(17) Fallon, K. J.; Budden, P.; Salvadori, E.; Ganose, A. M.; Savory, C. N.; Eyre, L.; Dowland, S.; Ai, Q.; Goodlett, S.; Risko, C.; Scanlon,
D. O.; Kay, C. W. M.; Rao, A.; Friend, R. H.; Musser, A. J.; Bronstein, H. Exploiting Excited-State Aromaticity to Design Highly Stable Singlet Fission Materials. J. Am. Chem. Soc. 2019, 141, 13867-13876.

(18) Baranac-Stojanović, M. Substituent Effect on Triplet State Aromaticity of Benzene. J. Org. Chem. 2020, 85, 4289-4297.

(19) Rosenberg, M.; Dahlstrand, C.; Kilså, K.; Ottosson, H. Excited State Aromaticity and Antiaromaticity: Opportunities for Photophysical and Photochemical Rationalizations. Chem. Rev. 2014, 114, $5379-5425$.

(20) Oruganti, B.; Wang, J.; Durbeej, B. Excited-State Aromaticity Improves Molecular Motors: A Computational Analysis. Org. Lett. 2017, 19, 4818-4821.

(21) Durbeej, B.; Wang, J.; Oruganti, B. Molecular Photoswitching Aided by Excited-State Aromaticity. ChemPlusChem 2018, 83, 958967.

(22) Wang, J.; Oruganti, B.; Durbeej, B. A Straightforward Route to Aromatic Excited States in Molecular Motors That Improves Photochemical Efficiency. ChemPhotoChem. 2019, 3, 450-460.

(23) Gutiérrez-Arzaluz, L.; Cortés-Guzmán, F.; Rocha-Rinza, T.; Peón, J. Ultrafast Excited State Hydrogen Atom Transfer in Salicylideneaniline Driven by Changes in Aromaticity. Phys. Chem. Chem. Phys. 2015, 17, 31608-31612.

(24) Nishina, N.; Mutai, T.; Aihara, J. Excited-State Intramolecular Proton Transfer and Global Aromaticity. J. Phys. Chem. A 2017, 121, $151-161$.

(25) Wu, C.-H.; Karas, L. J.; Ottosson, H.; Wu, J. I.-C. Excited-State Proton Transfer Relieves Antiaromaticity in Molecules. Proc. Natl. Acad. Sci. U. S. A. 2019, 116, 20303-20308.

(26) Skov, A. B.; Ree, N.; Gertsen, A. S.; Chabera, P.; Uhlig, J.; Lissau, J. S.; Nucci, L.; Pullerits, T.; Mikkelsen, K. V.; Brøndsted Nielsen, M.; Sølling, T. I.; Hansen, T. Excited-State Topology Modifications of the Dihydroazulene Photoswitch Through Aromaticity. ChemPhotoChem 2019, 3, 619-629.

(27) Hada, M.; Saito, S.; Tanaka, S.; Sato, R.; Yoshimura, M.; Mouri, K.; Matsuo, K.; Yamaguchi, S.; Hara, M.; Hayashi, Y.; Röhricht, F.; Herges, R.; Shigeta, Y.; Onda, K.; Miller, R. J. D. Structural Monitoring of the Onset of Excited-State Aromaticity in a Liquid Crystal Phase. J. Am. Chem. Soc. 2017, 139, 15792-15800.

(28) Yamakado, T.; Takahashi, S.; Watanabe, K.; Matsumoto, Y.; Osuka, A.; Saito, S. Conformational Planarization versus Singlet Fission: Distinct Excited-State Dynamics of Cyclooctatetraene-Fused Acene Dimers. Angew. Chem., Int. Ed. 2018, 57, 5438-5443.

(29) Toldo, J.; El Bakouri, O.; Solà, M.; Norrby, P.-O.; Ottosson, H. Is Excited-State Aromaticity a Driving Force for Planarization of Dibenzannelated $8 \pi$-Electron Heterocycles? ChemPlusChem 2019, 84, $712-721$.

(30) Banerjee, A.; Halder, D.; Ganguly, G.; Paul, A. Deciphering the Cryptic Role of a Catalytic Electron in a Photochemical Bond Dissociation Using Excited State Aromaticity Markers. Phys. Chem. Chem. Phys. 2016, 18, 25308-25314.

(31) Nakamura, S.; Irie, M. Thermally Irreversible Photochromic Systems. A Theoretical Study. J. Org. Chem. 1988, 53, 6136-6138.

(32) Irie, M.; Mohri, M. Thermally Irreversible Photochromic Systems. Reversible Photocyclization of Diarylethene Derivatives. J. Org. Chem. 1988, 53, 803-808.

(33) Irie, M.; Sakemura, K.; Okinaka, M.; Uchida, K. Photochromism of Dithienylethenes with Electron-Donating Substituents. J. Org. Chem. 1995, 60, 8305-8309.

(34) Irie, M. Diarylethenes for Memories and Switches. Chem. Rev. 2000, 100, 1685-1716.

(35) Laurent, A. D.; André, J. M.; Perpète, E. A.; Jacquemin, D. Photochromic Properties of Dithienylazoles and Other Conjugated Diarylethenes. J. Photochem. Photobiol., A 2007, 192, 211-219.

(36) Ward, C. L.; Elles, C. G. Controlling the Excited-State Reaction Dynamics of a Photochromic Molecular Switch with Sequential TwoPhoton Excitation. J. Phys. Chem. Lett. 2012, 3, 2995-3000.

(37) Fihey, A.; Perrier, A.; Maurel, F. Tuning the Optical Properties of Dithienylethenes: Theoretical Insights. J. Photochem. Photobiol., A 2012, 247, 30-41. 
(38) Irie, M.; Fukaminato, T.; Matsuda, K.; Kobatake, S. Photochromism of Diarylethene Molecules and Crystals: Memories, Switches, and Actuators. Chem. Rev. 2014, 114, 12174-12277.

(39) Bléger, D.; Hecht, S. Visible-Light-Activated Molecular Switches. Angew. Chem., Int. Ed. 2015, 54, 11338-11349.

(40) Sud, D.; Wigglesworth, T. J.; Branda, N. R. Creating a Reactive Enediyne by Using Visible Light: Photocontrol of the Bergman Cyclization. Angew. Chem., Int. Ed. 2007, 46, 8017-8019.

(41) Lerch, M. M.; Hansen, M. J.; van Dam, G. M.; Szymanski, W.; Feringa, B. L. Emerging Targets in Photopharmacology. Angew. Chem., Int. Ed. 2016, 55, 10978-10999.

(42) Li, J.; Speyer, G.; Sankey, O. F. Conduction Switching of Photochromic Molecules. Phys. Rev. Lett. 2004, 93, 248302.

(43) Tian, H.; Feng, Y. Next Step of Photochromic Switches? J. Mater. Chem. 2008, 18, 1617-1622.

(44) Milek, M.; Heinemann, F. W.; Khusniyarov, M. M. Spin Crossover Meets Diarylethenes: Efficient Photoswitching of Magnetic Properties in Solution at Room Temperature. Inorg. Chem. 2013, 52, 11585-11592.

(45) Hamdi, I.; Buntinx, G.; Poizat, O.; Perrier, A.; Le Bras, L.; Delbaere, S.; Barrau, S.; Louati, M.; Takeshita, M.; Tokushige, K.; Takao, M.; Aloïse, S. Excited-State Dynamics of Dithienylethenes Functionalized for Self-Supramolecular Assembly. J. Phys. Chem. A 2018, 122, 3572-3582.

(46) Hassan, Z.; Matt, Y.; Begum, S.; Tsotsalas, M.; Bräse, S. Assembly of Molecular Building Blocks into Integrated Complex Functional Molecular Systems: Structuring Matter Made to Order. Adv. Funct. Mater. 2020, 30, 1907625.

(47) Wang, Z.; Roffey, A.; Losantos, R.; Lennartson, A.; Jevric, M.; Petersen, A. U.; Quant, M.; Dreos, A.; Wen, X.; Sampedro, D.; Börjesson, K.; Moth-Poulsen, K. Macroscopic Heat Release in a Molecular Solar Thermal Energy Storage System. Energy Environ. Sci. 2019, 12, 187-193.

(48) Hansen, M. H.; Elm, J.; Olsen, S. T.; Gejl, A. N.; Storm, F. E.; Frandsen, B. N.; Skov, A. B.; Nielsen, M. B.; Kjaergaard, H. G.; Mikkelsen, K. V. Theoretical Investigation of Substituent Effects on the Dihydroazulene/Vinylheptafulvene Photoswitch: Increasing the Energy Storage Capacity. J. Phys. Chem. A 2016, 120, 9782-9793.

(49) Mansø, M.; Petersen, A. U.; Wang, Z.; Erhart, P.; Nielsen, M. B.; Moth-Poulsen, K. Molecular Solar Thermal Energy Storage in Photoswitch Oligomers Increases Energy Densities and Storage Times. Nat. Commun. 2018, 9, 1945.

(50) Jevric, M.; Petersen, A. U.; Mansø, M.; Kumar Singh, S.; Wang, Z.; Dreos, A.; Sumby, C.; Nielsen, M. B.; Börjesson, K.; Erhart, P.; Moth-Poulsen, K. Norbornadiene-Based Photoswitches with Exceptional Combination of Solar Spectrum Match and Long-Term Energy Storage. Chem. - Eur. J. 2018, 24, 12767-12772.

(51) Milić, J. V.; Schaack, C.; Hellou, N.; Isenrich, F.; GershoniPoranne, R.; Neshchadin, D.; Egloff, S.; Trapp, N.; Ruhlmann, L.; Boudon, C.; Gescheidt, G.; Crassous, J.; Diederich, F. LightResponsive Pyrazine-Based Systems: Probing Aromatic Diarylethene Photocyclization. J. Phys. Chem. C 2018, 122, 19100-19109.

(52) Karadakov, P. B.; Hearnshaw, P.; Horner, K. E. Magnetic Shielding, Aromaticity, Antiaromaticity, and Bonding in the LowLying Electronic States of Benzene and Cyclobutadiene. J. Org. Chem. 2016, 81, 11346-11352.

(53) Kitagawa, D.; Nakahama, T.; Nakai, Y.; Kobatake, S. 1,2Diarylbenzene as Fast T-Type Photochromic Switch. J. Mater. Chem. C 2019, 7, 2865-2870.

(54) Rungtaweevoranit, B.; Butsuri, A.; Wongma, K.; Sadorn, K.; Neranon, K.; Nerungsi, C.; Thongpanchang, T. A Facile Two-Step Synthesis of Thiophene End-Capped Aromatic Systems. Tetrahedron Lett. 2012, 53, 1816-1818.

(55) Marenich, A. V.; Cramer, C. J.; Truhlar, D. G. Universal Solvation Model Based on Solute Electron Density and on a Continuum Model of the Solvent Defined by the Bulk Dielectric Constant and Atomic Surface Tensions. J. Phys. Chem. B 2009, 113, 6378-6396.
(56) Spellmeyer, D. C.; Houk, K. N.; Rondan, N. G.; Miller, R. D.; Franz, L.; Fickes, G. N. Experimental and Theoretical Studies of Substituent Effects on an Orbital Symmetry Forbidden Electrocyclization. J. Am. Chem. Soc. 1989, 111, 5356-5367.

(57) Williams, R. V.; Edwards, W. D.; Mitchell, R. H.; Robinson, S. G. A DFT Study of the Thermal, Orbital Symmetry Forbidden, Cyclophanediene to Dihydropyrene Electrocyclic Reaction. Predictions to Improve the Dimethyldihydropyrene Photoswitches. J. Am. Chem. Soc. 2005, 127, 16207-16214.

(58) Khan, N.; Sheikh, N. S.; Khan, A. F.; Ludwig, R.; Mahmood, T.; Rehman, W.; Al-Faiyz, Y. S. S.; Ayub, K. Towards Thermally Stable Cyclophanediene-Dihydropyrene Photoswitches. J. Mol. Model. 2015, 21, 148.

(59) Mahmood, T.; Kosar, N.; Ayub, K. DFT Study of Acceleration of Electrocyclization in Photochromes under Radical Cationic Conditions: Comparison with Recent Experimental Data. Tetrahedron 2017, 73, 3521-3528.

(60) Huix-Rotllant, M.; Filatov, M.; Gozem, S.; Schapiro, I.; Olivucci, M.; Ferré, N. Assessment of Density Functional Theory for Describing the Correlation Effects on the Ground and Excited State Potential Energy Surfaces of a Retinal Chromophore Model. J. Chem. Theory Comput. 2013, 9, 3917-3932.

(61) Andersson, K.; Malmqvist, P.-Å.; Roos, B. O.; Sadlej, A. J.; Wolinski, K. Second-Order Perturbation Theory with a CASSCF Reference Function. J. Phys. Chem. 1990, 94, 5483-5488.

(62) Finley, J.; Malmqvist, P.-Å.; Roos, B. O.; Serrano-Andrés, L. The Multi-State CASPT2 Method. Chem. Phys. Lett. 1998, 288, 299306.

(63) Barbatti, M. Nonadiabatic Dynamics with Trajectory Surface Hopping Method. WIREs Comput. Mol. Sci. 2011, 1, 620-633.

(64) Tapavicza, E.; Meyer, A. M.; Furche, F. Unravelling the Details of Vitamin D Photosynthesis by Non-Adiabatic Molecular Dynamics Simulations. Phys. Chem. Chem. Phys. 2011, 13, 20986-20998.

(65) Tapavicza, E.; Bellchambers, G. D.; Vincent, J. C.; Furche, F. Ab Initio Non-Adiabatic Molecular Dynamics. Phys. Chem. Chem. Phys. 2013, 15, 18336-18348.

(66) Rauer, C.; Nogueira, J. J.; Marquetand, P.; González, L. Cyclobutane Thymine Photodimerization Mechanism Revealed by Nonadiabatic Molecular Dynamics. J. Am. Chem. Soc. 2016, 138, 15911-15916.

(67) Curchod, B. F. E.; Martínez, T. J. Ab Initio Nonadiabatic Quantum Molecular Dynamics. Chem. Rev. 2018, 118, 3305-3336.

(68) Tully, J. C. Molecular Dynamics with Electronic Transitions. J. Chem. Phys. 1990, 93, 1061-1071.

(69) Bertarelli, C.; Gallazzi, M. C.; Stellacci, F.; Zerbi, G.; Stagira, S.; Nisoli, M.; De Silvestri, S. Ultrafast Photoinduced Ring-Closure Dynamics of a Diarylethene Polymer. Chem. Phys. Lett. 2002, 359, 278-282.

(70) Jean-Ruel, H.; Cooney, R. R.; Gao, M.; Lu, C.; Kochman, M. A.; Morrison, C. A.; Miller, R. J. D. Femtosecond Dynamics of the Ring Closing Process of Diarylethene: A Case Study of Electrocyclic Reactions in Photochromic Single Crystals. J. Phys. Chem. A 2011, $115,13158-13168$.

(71) Ishibashi, Y.; Fujiwara, M.; Umesato, T.; Saito, H.; Kobatake, S.; Irie, M.; Miyasaka, H. Cyclization Reaction Dynamics of a Photochromic Diarylethene Derivative as Revealed by Femtosecond to Microsecond Time-Resolved Spectroscopy. J. Phys. Chem. C 2011, $115,4265-4272$.

(72) Jean-Ruel, H.; Gao, M.; Kochman, M. A.; Lu, C.; Liu, L. C.; Cooney, R. R.; Morrison, C. A.; Miller, R. J. D. Ring-Closing Reaction in Diarylethene Captured by Femtosecond Electron Crystallography. J. Phys. Chem. B 2013, 117, 15894-15902.

(73) Kruszewski, J.; Krygowski, T. M. Definition of Aromaticity Basing on the Harmonic Oscillator Model. Tetrahedron Lett. 1972, 13, 3839-3842.

(74) Krygowski, T. M. Crystallographic Studies of Inter- and Intramolecular Interactions Reflected in Aromatic Character of $\pi$ Electron Systems. J. Chem. Inf. Model. 1993, 33, 70-78. 
(75) Krygowski, T. M.; Cyrański, M. K. Structural Aspects of Aromaticity. Chem. Rev. 2001, 101, 1385-1419.

(76) Noorizadeh, S.; Shakerzadeh, E. Shannon Entropy as a New Measure of Aromaticity, Shannon Aromaticity. Phys. Chem. Chem. Phys. 2010, 12, 4742-4749.

(77) Noorizadeh, S.; Shakerzadeh, E. Aromaticity Study on Tria-, Penta- and Hepta-Fulvene Derivatives. Comput. Theor. Chem. 2011, 964, 141-147.

(78) Bader, R. F. W. A Quantum Theory of Molecular Structure and Its Applications. Chem. Rev. 1991, 91, 893-928.

(79) Schleyer, P. v. R.; Maerker, C.; Dransfeld, A.; Jiao, H.; van Eikema Hommes, N. J. R. Nucleus-Independent Chemical Shifts : A Simple and Efficient Aromaticity Probe. J. Am. Chem. Soc. 1996, 118, 6317-6318.

(80) Fallah-Bagher-Shaidaei, H.; Wannere, C. S.; Corminboeuf, C.; Puchta, R.; Schleyer, P. v. R. Which NICS Aromaticity Index for Planar $\pi$ Rings is Best? Org. Lett. 2006, 8, 863-866.

(81) Stanger, A. Nucleus-Independent Chemical Shifts (NICS): Distance Dependence and Revised Criteria for Aromaticity and Antiaromaticity. J. Org. Chem. 2006, 71, 883-893.

(82) Gershoni-Poranne, R.; Stanger, A. The NICS-XY-Scan: Identification of Local and Global Ring Currents in Multi-Ring Systems. Chem. - Eur. J. 2014, 20, 5673-5688.

(83) Roos, B. O.; Taylor, P. R.; Sigbahn, P. E.M. A Complete Active Space SCF Method (CASSCF) Using a Density Matrix Formulated Super-CI Approach. Chem. Phys. 1980, 48, 157-173.

(84) Schleyer, P. v. R.; Puhlhofer, F. Recommendations for the Evaluation of Aromatic Stabilization Energies. Org. Lett. 2002, 4, $2873-2876$

(85) Jorner, K.; Emanuelsson, R.; Dahlstrand, C.; Tong, H.; Denisova, A. V.; Ottosson, H. Impact of Ground- and Excited-State Aromaticity on Cyclopentadiene and Silole Excitation Energies and Excited-State Polarities. Chem. - Eur. J. 2014, 20, 9295-9303.

(86) Runge, E.; Gross, E. K. U. Denisty-Functional Theory for Time-Dependent Systems. Phys. Rev. Lett. 1984, 52, 997-1000.

(87) Bauernschmitt, R.; Ahlrichs, R. Treatment of Electronic Excitations within the Adiabatic Approximation of Time Dependent Density Functional Theory. Chem. Phys. Lett. 1996, 256, 454-464.

(88) Casida, M. E.; Jamorski, C.; Casida, K. C.; Salahub, D. R. Molecular Excitation Energies to High-Lying Bound States from Time-Dependent Density-Functional Response Theory: Characterization and Correction of the Time-Dependent Local Density Approximation Ionization Threshold. J. Chem. Phys. 1998, 108, 4439-4449.

(89) Stratmann, R. E.; Scuseria, G. E.; Frisch, M. J. An Efficient Implementation of Time-Dependent Density-Functional Theory for the Calculation of Excitation Energies of Large Molecules. J. Chem. Phys. 1998, 109, 8218-8224.

(90) Furche, F.; Ahlrichs, R. Adiabatic Time-Dependent Density Functional Methods for Excited State Properties. J. Chem. Phys. 2002, 117, 7433-7447.

(91) Marques, M. A. L.; Gross, E. K. U. Time-Dependent Density Functional Theory. Annu. Rev. Phys. Chem. 2004, 55, 427-455.

(92) Chiba, M.; Tsuneda, T.; Hirao, K. Excited State Geometry Optimizations by Analytical Energy Gradient of Long-Range Corrected Time-Dependent Density Functional Theory. J. Chem. Phys. 2006, 124, 144106.

(93) Casida, M. E. Time-Dependent Density-Functional Theory for Molecules and Molecular Solids. J. Mol. Struct.: THEOCHEM 2009, $914,3-18$.

(94) Casida, M. E.; Huix-Rotllant, M. Progress in Time-Dependent Density-Functional Theory. Annu. Rev. Phys. Chem. 2012, 63, 287323.

(95) Lee, C.; Yang, W.; Parr, R. G. Development of The ColleSalvetti Correlation-Energy Formula into a Functional of the Electron Density. Phys. Rev. B: Condens. Matter Mater. Phys. 1988, 37, 785789.

(96) Becke, A. D. Density-functional thermochemistry. III. The role of exact exchange. J. Chem. Phys. 1993, 98, 5648-5652.
(97) Zhao, Y.; Truhlar, D. G. Density Functional for Spectroscopy: No Long-Range Self-Interaction Error, Good Performance for Rydberg and Charge-Transfer States, and Better Performance on Average than B3LYP for Ground States. J. Phys. Chem. A 2006, 110, 13126-13130.

(98) Zhao, Y.; Truhlar, D. G. The M06 Suite of Density Functionals for Main Group Thermochemistry, Thermochemical Kinetics, Noncovalent Interactions, Excited States, and Transition Elements: Two New Functionals and Systematic Testing of Four M06-Class Functionals and 12 Other Functionals. Theor. Chem. Acc. 2008, 120, 215-241.

(99) Chai, J.-D.; Head-Gordon, M. Long-Range Corrected Hybrid Density Functionals with Damped Atom-Atom Dispersion Corrections. Phys. Chem. Chem. Phys. 2008, 10, 6615-6620.

(100) Yanai, T.; Tew, D. P.; Handy, N. C. A New Hybrid Exchange-correlation Functional Using the Coulomb-Attenuating Method (CAM-B3LYP). Chem. Phys. Lett. 2004, 393, 51-57.

(101) Hirata, S.; Head-Gordon, M. Time-Dependent Density Functional Theory within the Tamm-Dancoff Approximation. Chem. Phys. Lett. 1999, 314, 291-299.

(102) Wang, Y.-L.; Wu, G.-S. Improving the TDDFT Calculation of Low-Lying Excited States for Polycyclic Aromatic Hydrocarbons Using the Tamm-Dancoff Approximation. Int. J. Quantum Chem. 2008, 108, 430-439.

(103) Isborn, C. M.; Luehr, N.; Ufimtsev, I. S.; Martínez, T. J. Excited-State Electronic Structure with Configuration Interaction Singles and Tamm-Dancoff Time-Dependent Density Functional Theory on Graphical Processing Units. J. Chem. Theory Comput. 2011, 7, 1814-1823.

(104) Chantzis, A.; Laurent, A. D.; Adamo, C.; Jacquemin, D. Is the Tamm-Dancoff Approximation Reliable for the Calculation of Absorption and Fluorescence Band Shapes? J. Chem. Theory Comput. 2013, 9, 4517-4525.

(105) Rostov, I. V.; Amos, R. D.; Kobayashi, R.; Scalmani, G.; Frisch, M. J. Studies of the Ground and Excited-State Surfaces of the Retinal Chromophore Using CAM-B3LYP. J. Phys. Chem. B 2010, 114, 5547-5555.

(106) Rostov, I. V.; Kobayashi, R.; Amos, R. D. Comparing LongRange Corrected Functionals in the Cis-Trans Isomerisation of the Retinal Chromophore. Mol. Phys. 2012, 110, 2329-2336.

(107) Grimme, S. Accurate Description of van der Waals Complexes by Density Functional Theory Including Empirical Corrections. J. Comput. Chem. 2004, 25, 1463-1473.

(108) Antony, J.; Grimme, S. Density Functional Theory Including Dispersion Corrections for Intermolecular Interactions in a Large Benchmark Set of Biologically Relevant Molecules. Phys. Chem. Chem. Phys. 2006, 8, 5287-5293.

(109) Furche, F.; Ahlrichs, R.; Hättig, C.; Klopper, W.; Sierka, M.; Weigend, F. Turbomole. WIREs Comput. Mol. Sci. 2014, 4, 91-100.

(110) Stanger, A. Reexamination of NICS $\pi, \mathrm{zz}$ : Height Dependence, Off-Center Values, and Integration. J. Phys. Chem. A 2019, 123, 3922-3927.

(111) Frisch, M. J.; et al. Gaussian 16, revision B.01; Gaussian, Inc.: Wallingford, CT, 2016

(112) Fdez Galván, I.; Vacher, M.; Alavi, A.; Angeli, C.; Aquilante, F.; Autschbach, J.; Bao, J. J.; Bokarev, S. I.; Bogdanov, N. A.; Carlson, R. K.; Chibotaru, L. F.; Creutzberg, J.; Dattani, N.; Delcey, M. G.; Dong, S. S.; Dreuw, A.; Freitag, L.; Frutos, L. M.; Gagliardi, L.; Gendron, F.; Giussani, A.; González, L.; Grell, G.; Guo, M.; Hoyer, C. E.; Johansson, M.; Keller, S.; Knecht, S.; Kovačević, G.; Källman, E.; Li Manni, G.; Lundberg, M.; Ma, Y.; Mai, S.; Malhado, J. P.; Malmqvist, P. A.; Marquetand, P.; Mewes, S. A.; Norell, J.; Olivucci, M.; Oppel, M.; Phung, Q. M.; Pierloot, K.; Plasser, F.; Reiher, M.; Sand, A. M.; Schapiro, I.; Sharma, P.; Stein, C. J.; Sørensen, L. K.; Truhlar, D. G.; Ugandi, M.; Ungur, L.; Valentini, A.; Vancoillie, S.; Veryazov, V.; Weser, O.; Wesołowski, T. A.; Widmark, P.-O.; Wouters, S.; Zech, A.; Zobel, J. P.; Lindh, R. OpenMolcas: From Source Code to Insight. J. Chem. Theory Comput. 2019, 15, 59255964. 
(113) TURBOMOLE V7.4 2019, a Development of University of Karlsruhe and Forschungszentrum Karlsruhe GmbH, 1989-2007, TURBOMOLE GmbH, since 2007; available from http://www. turbomole.com (accessed May 13, 2020).

(114) Aidas, K.; Angeli, C.; Bak, K. L.; Bakken, V.; Bast, R.; Boman, L.; Christiansen, O.; Cimiraglia, R.; Coriani, S.; Dahle, P.; Dalskov, E. K.; Ekström, U.; Enevoldsen, T.; Eriksen, J. J.; Ettenhuber, P.; Fernández, B.; Ferrighi, L.; Fliegl, H.; Frediani, L.; Hald, K.; Halkier, A.; Hättig, C.; Heiberg, H.; Helgaker, T.; Hennum, A. C.; Hettema, H.; Hjertenæs, E.; Høst, S.; Høyvik, I.-M.; Iozzi, M. F.; Jansik, B.; Jensen, H. J. A.; Jonsson, D.; Jørgensen, P.; Kauczor, J.; Kirpekar, S.; Kjærgaard, T.; Klopper, W.; Knecht, S.; Kobayashi, R.; Koch, H.; Kongsted, J.; Krapp, A.; Kristensen, K.; Ligabue, A.; Lutnæs, O. B.; Melo, J. I.; Mikkelsen, K. V.; Myhre, R. H.; Neiss, C.; Nielsen, C. B.; Norman, P.; Olsen, J.; Olsen, J. M. H.; Osted, A.; Packer, M. J.; Pawlowski, F.; Pedersen, T. B.; Provasi, P. F.; Reine, S.; Rinkevicius, Z.; Ruden, T. A.; Ruud, K.; Rybkin, V. V.; Salek, P.; Samson, C. C. M.; de Merás, A. S.; Saue, T.; Sauer, S. P. A.; Schimmelpfennig, B.; Sneskov, K.; Steindal, A. H.; Sylvester-Hvid, K. O.; Taylor, P. R.; Teale, A. M.; Tellgren, E. I.; Tew, D. P.; Thorvaldsen, A. J.; Thøgersen, L.; Vahtras, O.; Watson, M. A.; Wilson, D. J. D.; Ziolkowski, M.; Ågren, H. The Dalton Quantum Chemistry Program System. WIREs Comput. Mol. Sci. 2014, 4, 269-284.

(115) Dalton, A. Molecular Electronic Structure Program, Release Dalton 2016.2 (2016); see http://daltonprogram.org (accessed May 13, 2020).

(116) Lu, T.; Chen, F. Multiwfn: A Multifunctional Wavefunction Analyzer. J. Comput. Chem. 2012, 33, 580-592. 